\title{
The WRAD complex represents a therapeutically exploitable target for cancer stem cells in glioblastoma
}

Kelly Mitchell ${ }^{1,2}$, Sajina Shakya ${ }^{3}$, Daniel J. Silver ${ }^{1,2}$, Christopher M. Goins ${ }^{4}$, Lisa Wallace ${ }^{2}$, Gustavo Roversi $^{1,5}$, Rachel Schafer ${ }^{1,5}$, Kristen Kay ${ }^{1}$, Tyler E. Miller ${ }^{8}$, Adam Lauko ${ }^{1,5,6,7}$, J. D'Amato Kass ${ }^{1}$, Anjali Kashyap ${ }^{1}$, Erin E. Mulkearns-Hubert ${ }^{1,5}$, Sadie Johnson ${ }^{1}$, Joseph Alvarado ${ }^{4}$, Jeremy N.

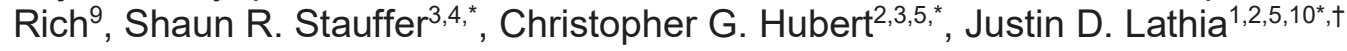

Departments of ${ }^{1}$ Cardiovascular \& Metabolic Sciences and ${ }^{3}$ Biomedical Engineering, Lerner Research Institute, Cleveland Clinic, Cleveland, OH, USA

${ }^{2}$ Case Comprehensive Cancer Center, Cleveland, OH, USA

${ }^{4}$ Center for Therapeutics Discovery, Lerner Research Institute, Cleveland Clinic, Cleveland, $\mathrm{OH}$, USA

${ }^{5}$ Cleveland Clinic Lerner College of Medicine of Case Western Reserve University, Cleveland, $\mathrm{OH}$, USA

${ }^{6}$ Department of Pathology, Case Western Reserve University, Cleveland, OH, USA;

${ }^{7}$ Medical Scientist Training Program, Case Western Reserve University School of Medicine, Cleveland, $\mathrm{OH}$, USA.

${ }^{8}$ Department of Pathology, Massachusetts General Hospital, Boston, MA; Department of Cancer Biology, Dana Farber Cancer Institute, Boston, MA, USA

${ }^{9}$ UPMC Hillman Cancer Center and University of Pittsburgh School of Medicine, Pittsburgh, PA, USA

${ }^{10}$ Rose Ella Burkhardt Brain Tumor and Neuro-Oncology Center, Cleveland Clinic, Cleveland, $\mathrm{OH}$, USA

${ }^{*}$ Corresponding author, ${ }^{+}$Lead contact

Corresponding authors' contact information:

Justin D. Lathia

Department of Cardiovascular \& Metabolic Sciences

Lerner Research Institute, Cleveland Clinic

lathiaj@ccf.org

Christopher G. Hubert

Department of Biomedical Engineering

Lerner Research Institute, Cleveland Clinic

hubertc@ccf.org

Shaun R. Stauffer

Center for Therapeutics Discovery

Lerner Research Institute, Cleveland Clinic

stauffs2@ccf.org 


\section{Summary}

Glioblastomas (GBMs) are heterogeneous, treatment-resistant tumors that are driven by populations of cancer stem cells (CSCs). Despite their importance for tumor growth, few molecular mechanisms critical for CSC population maintenance have been exploited for therapeutic development. We employed spatially resolved loss-of-function screening in GBM patient-derived organoids to identify essential epigenetic regulators and identified WDR5 as indispensable for CSCs. WDR5 is a component of the WRAD complex, which promotes SET1family-mediated Lys4 methylation of histone $\mathrm{H} 3$, associated with positive regulation of transcription. Genetic and pharmacologic inhibition of WDR5 reduced growth and self-renewal of CSCs as well as CSC-mediated tumor growth. Further, WDR5 inhibitors partially blocked WRAD complex assembly, reduced H3K4 trimethylation, and inhibited tumor growth. These findings highlight the role of WDR5 and the WRAD complex in CSCs for maintaining the CSC state and provide a rationale for therapeutic development of WRAD complex inhibitors for GBM and other advanced cancers. 


\section{Introduction}

Glioblastoma (GBM) is the most common primary malignant brain tumor and remains highly lethal despite an aggressive multi-modal standard-of-care approach that includes maximal safe surgical resection followed by concomitant radiation and chemotherapy. GBM tumors display profound cellular heterogeneity, with both tumor growth and therapeutic resistance driven by populations of cells with stem-cell like properties that are termed cancer stem cells (CSCs) (reviewed in (Mitchell et al., 2021)). Neurodevelopmental transcription factors such as SOX2, POU3F2, SALL2, and OLIG2 are expressed in subpopulations of GBM tumor cells, are necessary and sufficient for tumor propagation in vivo, and cooperate to maintain stem cell-like epigenetic landscapes (Singh et al., 2017; Suva et al., 2014). Such epigenetic regulation controls the access of transcription factors to defined sets of genes and allows for the transition of cells between states (Huang, 2013; Singh et al., 2017). Thus, aberrant expression of core transcription factors may coordinate expression of epigenetic regulatory machinery, together promoting maintenance of the CSC state in GBM.

Studies profiling DNA methylation and histone modifications in GBM have revealed common transcription factor networks and epigenetic profiles across primary patient tumors (Guilhamon et al., 2021; Hall et al., 2018; Mack et al., 2019; Yoo and Bieda, 2014). Specific DNA methylation, histone methylation, histone acetylation, and chromatin accessibility patterns are predictive of patient response to therapy (Dahlrot et al., 2018; Guilhamon et al., 2021; Hall et al., 2018; Mack et al., 2019; Thon et al., 2013). GBM cell state plasticity in response to external stimuli such as therapeutic pressure is facilitated, at least in part, by chromatin reorganization (Liau et al., 2017). Accordingly, several epigenetic regulators are elevated in GBM CSCs and are necessary and sufficient for self-renewal. These include retinoblastoma binding protein 5 (RBBP5), which we previously showed to control the core pluripotency transcription factors SOX2, OCT4 and NANOG 
(Alvarado et al., 2017), mixed lineage leukemia 1 (MLL1) (Gallo et al., 2013; Heddleston et al., 2012), DPY30 (Miller et al., 2017), BMI1 (Abdouh et al., 2009), EZH2 (Suva et al., 2009), KDM1A/LSD1 (Suva et al., 2014), KDM6B/JMJD3, HELLS, TET3, and TRIM24 (reviewed in (Valor and Hervas-Corpion, 2020)). It is likely that these epigenetic regulators generate permissive chromatin states that then facilitate transcriptional plasticity in tumor cell populations, including maintenance of the CSC state amidst cell-cell interactions, cell-environmental interactions and therapeutic pressures (Flavahan et al., 2017).

3D organoid models of GBM recapitulate a variety of cellular states seen in primary patient tumors, including niches of SOX2+ CSCs, and allow for interaction of cells in various states in an in vitro system (Hubert et al., 2016). To elucidate epigenetic factors responsible for maintenance of the CSC state in GBM in the context of heterogeneous cell populations and CSC niches, we employed an unbiased organoid-based screen targeting epigenetic regulators. Through this screen, we identified WDR5 as a key CSC regulator and validated its functional necessity for CSC self-renewal and tumor initiation. WDR5 is a member of the WRAD complex, which also includes RBBP5, ASH2L, and DPY30, two of which were previously found to be important for the GBM CSC state (Alvarado et al., 2017; Miller et al., 2017). The WRAD complex interacts with methyltransferases and other epigenetic modifiers, including MLL1, to facilitate post-translational modifications on histone tails, subsequently affecting transcriptional dynamics (Ruthenburg et al., 2006; Wysocka et al., 2005). These modifications include histone 3 lysine 4 (H3K4) mono-, di-, and tri-methylation as well as histone 4 lysine 16 acetylation (Guarnaccia and Tansey, 2018). Given the importance of the WRAD complex as a key cancer regulator, attempts have been made to inhibit its function based on the hypothesis that targeting the WRAD complex could compromise the ability for a tumor cell to maintain a favorable epigenetic state (Aho et al., 2019b; Lu et al., 2018). This strategy provides an alternative approach to directly inhibiting core pluripotency 
transcription factors, especially the transcriptional master regulator and GBM CSC marker SOX2, that regulate CSCs but are challenging to individually target due to their complex and varied interactions with proteins and DNA (Gangemi et al., 2009). The WRAD complex is highly conserved and has been demonstrated to regulate developmental differentiation (Ang et al., 2011). It is also functionally important in a variety of cancers, including acute myeloid leukemia (AML) (Aho et al., 2019b). Here, we hypothesized that targeting this complex could be a means to disrupt epigenetic programs that maintain the CSC transcriptional state. We leveraged a tool compound, compound 16 (C16), that targets the WDR5 WIN site (WDR5/MLL1-interaction site) to investigate WDR5 as a CSC target. C16 phenocopied WDR5 genetic loss of function and diminished histone 3 lysine 4 (H3K4) tri-methylation following dissociation of the WRAD complex. Our study provides proof of concept for targeting WDR5 to impair CSC population viability with limited toxicity in normal cell types. 


\section{Results}

Spatially resolved organoid screening reveals WDR5 is essential for CSC survival

GBM CSCs reside in defined tumor niches and display complex interactions with their microenvironment and surrounding cell populations (Bayik et al., 2020; Jacob et al., 2020; Lathia et al., 2015; Mitchell et al., 2021; Silver et al., 2021; Venkatesh et al., 2015; Zhang et al., 1999). To better model the cellular heterogeneity in GBM and capture the complex dependencies of CSCs, we leveraged an organoid culture system that allows for the simultaneous culture of GBM cells in diverse states, including the CSC state (Hubert et al., 2016). The outer rim of GBM organoids is highly enriched for functionally self-renewing SOX2+ CSCs compared to the inner core, representing two distinct growth zones that support the CSC phenotype to notably different degrees yet arise from a single population of GBM tumor cells (Fig. 1A-D). To isolate viable GBM populations from these separate zones, we developed a technique to regionally label GBM organoids. This method specifically and reliably labels the outer proliferative niche within each organoid using the fluorescent dye CellTracker Blue CMAC (Shakya et al., 2021). RNA sequencing of spatially isolated GBM cells from dissociated organoids reflects region-specific gene expression profiles from patient GBM tumors, and the SOX2-high organoid outer rim is functionally enriched for stem cell activity (Shakya et al., 2021). This SOX2+ GBM organoid rim is highly proliferative and the SOX2+ cells within this region are resistant to radiation therapy (Hubert et al., 2016). A wide range of patient-derived GBM organoid specimens demonstrated increased SOX2 expression within the highly proliferative rim region (S. Fig. 1A).

To discover new therapeutic targets within the SOX2-enriched population of the organoid, we adapted our methods to enable high-throughput functional screening in 3D culture. We used a pooled inducible lentiviral shRNA library to target $\sim 400$ epigenetic-modifying genes in several 
hundred GBM organoids in parallel and allowed the organoids to mature for 1 month in spinning bioreactors prior to shRNA induction and outgrowth (to avoid affecting cells prior to stable microenvironment formation) (S. Fig. 1B-C). Greater than 500-fold representation of library complexity was maintained at every step in the screened populations, and full screens were performed in triplicate. To isolate separate niche populations, we spatially labeled GBM organoids and verified proper organoid regional labeling using live confocal imaging (Fig. 1E-I) prior to organoid dissociation and FACS sorting (Fig. 1J). DNA was isolated from sorted populations, tagged with unique molecular barcodes, and deconvolved by high-throughput sequencing of the remaining integrated shRNA libraries as previously described (Miller et al., 2017). Genes identified by RIGER analysis (Broad Institute) as essential by organoid screening were retrospectively separated into overlapping or niche-specific targets based on prior regional labeling (Fig. 1K-L, S. Fig. 1D). Our positive control, RPA3 knockdown, is broadly cell lethal and was present in both cell niche populations. Since cell-lethal knockdowns common to both organoid regions are likely enriched for such universally required genes and therefore less likely to have a therapeutic window upon translation to therapy, we focused on genes uniquely essential in the GBM SOX2+ stem cell niche (Fig. 1K). This population included MLL5, a gene previously identified as critical for maintaining CSC self-renewal in GBM (Gallo et al., 2015), underscoring the capability of our screening platform to identify valid and biologically meaningful genes in GBM CSCs.

Our screen also identified the trithorax protein WD repeat domain 5 (WDR5), a core subunit of the WRAD complex that facilitates activity of human MLL and SET1 H3K4 methyltransferase complexes, as an essential gene for growth within the SOX2-enriched niche of GBM organoids. Previous studies demonstrated that WDR5 mediates self-renewal in embryonic stem cells by regulating the OCT4-SOX2-NANOG pluripotency transcription factor network (Ang et al., 2011). However while WDR5 appears to be expressed in GBM and neuroblastoma and functionally 
important in high-passage GBM models (Wang et al., 2020), WDR5 has not been extensively investigated in GBM CSCs or in the context of anti-GBM therapy.

We treated organoids with MM-102, a commercially available WDR5 WIN-site inhibitor (which targets the WIN site on WDR5, an arginine binding cavity that facilitates WDR5/MLL1 binding). MM-102 specifically inhibits WDR5 interaction with MLL1 (Karatas et al., 2013) and disrupts its interaction with RBBP5 (Patel et al., 2008), both of which have been implicated in GBM stem cell maintenance (Alvarado et al., 2017; Heddleston et al., 2012). We quantified cell proliferation in each organoid niche region using immunohistochemistry (IHC) for a mitotic marker (phosphorylated histone $\mathrm{H} 3, \mathrm{pHH} 3$ ) and scanning/tiling microscopy. MM-102 recapitulated the screen results, resulting in reduced pHH3+ cells (S. Fig. 2A).

WDR5 knockdown reduces CSC growth, self-renewal, and tumor initiation

Given the identification in our screen of WDR5 as essential for SOX2+ CSC survival, we turned to a series of patient-derived GBM xenograft models using conventional CSC-enriching culture conditions to more efficiently expand and validate the function of WDR5 in CSCs. We first sought to validate the expression of SOX2 in our CSC-enriching culture conditions (S. Fig. 2 B) and the presence of the WRAD complex in these models. By immunoprecipitation of either RBBP5 or WDR5 and immunoblotting for complex members, we were able to detect the presence of the WRAD complex in CSCs (Fig. 2A). Considering that MLL1 is specifically dependent on WDR5 for its methyltransferase activity (Alicea-Velazquez et al., 2016; Cao et al., 2014; Dou et al., 2006; Shinsky et al., 2015) and given the previously described role of MLL1 in GBM CSCs (Gallo et al., 2013; Heddleston et al., 2012), we additionally immunoblotted for MLL1 in this complex and found that it was present (Fig. 2A). Given our ability to detect the WRAD complex, we then tested how silencing WDR5 using short hairpin RNA (shRNA) interference (Fig. 2B) affected the stem cell 
behaviors of three of our patient-derived CSC models. Depletion of WDR5 protein using shRNA resulted in reduced cell growth (Fig. 2C, D) and attenuated self-renewal (Fig. 2E, S. Fig. 2C) compared to non-targeting (NT) controls. We further assessed in vivo tumor initiation in these conditions and found that a reduction in WDR5 increased tumor latency (Fig. 2F). Taken together, these data more broadly validate our initial organoid screening results, demonstrate that WDR5 is essential for the CSC phenotype, and provide a rationale for the pharmacological targeting of WDR5 and the WRAD complex.

Reduction of CSC viability, growth, and self-renewal via a WDR5 small molecule inhibitor

Given our observations that WDR5 is essential for CSC maintenance and the initial assessment of the WDR5 peptidomimetic inhibitor MM-102 in organoids, we further assessed MM-102 in CSCenriched PDX cultures and observed a reduction in CSC number and proliferation (S. Fig. 2D-E). However, the half-maximal inhibitory concentrations $\left(\mathrm{IC}_{50}\right)$ required for such a reduction ranged from 20-40 $\mu \mathrm{M}$ (Table 1), which we predict would pose a challenge for eventual clinical translation. As a large peptidomimetic, MM-102 is limited to an in vitro setting and clearly lacks the properties needed (e.g., passive permeability, CNS penetration, metabolic stability) to fully study the impact of WDR5 WIN-site inhibition in the context of GBM. To identify more potent WRAD complex inhibitors for GBM, we leveraged previously described WRAD complex small molecule inhibitors tested in other cancers, including AML, neuroblastoma and pancreatic ductal adenocarcinoma (Aho et al., 2019a; Sun et al., 2015; Tian et al., 2020; Zhang et al., 2018). These included piribedil and OICR-9429, which have not been assessed in GBM or CSCs but displayed IC 50 S similar to those observed with MM-102 (Table 1). We found varying responses to a previously disclosed compound known as 'compound 16' (Tian et al., 2020) (Fig. 3A), for brevity referred to as C16 hereafter, which showed the lowest $\mathrm{IC}_{50}$ compared with the other WDR5 inhibitors tested (Table 1). C16 was synthesized and obtained using published protocols (Tian et al., 2020). Using 
recombinantly expressed and purified WDR5, the C16 small molecule inhibitor robustly displaced a fluorescently labeled MLL1-derived peptide using the time-resolved fluorescence energy transfer (TR-FRET) assay (S. Fig. 3A). With binding affinity confirmed for C16, we next evaluated C16 over a panel of CSCs derived from our PDX models. Here, we observed $\mathrm{IC}_{50}$ values that ranged from 0.4-6.6 $\mu \mathrm{M}$ across CSCs from >8 PDX models (Fig. 3B). Given the role of the WRAD complex in normal stem cells (Ang et al., 2011; Lim et al., 2009), we tested C16 in transformed CB660 human neural stem cells. These cells have been modified via the following combinations of loss of tumor suppressors and addition of oncogenes: dominant-negative p53 ${ }^{\mathrm{DD}}$ and hTERT (noted as "PhT"), CyclinD1 and CDK4 ${ }^{\mathrm{R} 24 \mathrm{C}}$ (noted as "CC"), and MYC and H-RasV12, as previously described (Hubert et al., 2013). We found that sensitivity to C16 greatly increased as a result of exogenous MYC expression, and most acutely in MYC+RAS transformed cells (Fig. 3B, Table 1).

Based on these initial observations, we focused on a subset of CSCs from PDX models (3832, DI318 and L0) and found that C16 reduced cell number and increased apoptosis in a concentration-dependent manner (Fig 3C,D, S. Fig. 3B,C). Importantly, C16 also reduced CSC self-renewal in a concentration-dependent manner (Fig. 3E, S. Fig. 3D,E) and reduced CSC proliferation in 4 independent patient-derived GBM organoids (Fig. 3F). Finally, to initially assess in vivo toxicity, we dosed mice with $10 \mathrm{mg} / \mathrm{kg} \mathrm{C} 16$ daily and did not observe a significant reduction in weight over a 10-day period (S. Fig. 3F). Assessment of brain penetration via a snapshot brainto-plasma time course concentration profile after a single IP bolus dose of $10 \mathrm{mg} / \mathrm{kg}$ in CD-1 mice revealed limited brain penetration of $\mathrm{C} 16$, with an area under the curve brain-to-plasma ratio of less than $10 \%\left(A \cup C_{\text {brain }} / A \cup C_{\text {plasma }}\right.$ ratio < 0.1) (S. Fig. 3G). C16 was submitted to Absorption Systems Inc. for in vitro determination of blood-brain-barrier penetration potential using MDR1MDCK cell monolayers, a routine methodology used to predict the likelihood of passive CNS penetration. An average A-B passive permeability (Papp) of $0.715 \times 10^{-6} \mathrm{~cm} / \mathrm{sec}$ was measured for 
C16, a value that is indicative of low brain penetration potential classification. This in vitro observation is consistent with the observed in vivo AUCbrain/AUCplasma after a single IP administration. Typical CNS therapeutics maintain moderate to high passive permeability $\left(\mathrm{P}_{\mathrm{app}}\right.$ $>10 \times 10^{-6} \mathrm{~cm} / \mathrm{sec}$ ) and lack active transport/efflux from transporters expressed at the blood-brain barrier (Mahar Doan et al., 2002). Given these data, we leveraged a flank tumor model rather than a brain tumor model to test C16 in vivo. We found that both direct tumoral injection and systemic IP injection of C16 modestly reduced tumor volume (Fig. 3G-H).

To further interrogate the CSC state in response to C16, we utilized the SORE6 CSC reporter, an established system that is activated in response to binding to 6 tandem repeats of SOX2 and OCT4 binding elements on the NANOG promoter (Fig. 4A) (Tang et al., 2015). While this system has been utilized as a tool in a variety of tumors (Koshkin et al., 2021; Li et al., 2021; Menendez et al., 2020; Padua et al., 2020; Pudelko et al., 2017; Tang et al., 2015; Vaddi et al., 2019), it has not yet been employed to inform the GBM CSC phenotype. We transduced our CSC models with this reporter and found that SORE6-GFP-high cells gave rise to both GFP-high and GFP-low cells, with GFP-high cells having a higher self-renewal frequency (S. Fig. 4A). SORE6-GFP-high cells also had elevated SOX2 expression (S. Fig. 4B). Direct visualization of C16 treatment in SORE6-transduced GBM cells revealed a decrease in the number of GFP+ cells over time (Fig. 4B-D). Taken together, these data provide proof of concept that targeting of the WRAD complex suppresses the CSC phenotype.

WDR5 small molecule inhibition reduces the interaction between WDR5 and WRAD complex members and diminishes the histone 3 lysine 4 trimethylation (H3K4me3) mark

To gain further insight into the C16 mechanism of action, we performed co-immunoprecipitation studies in the presence of the inhibitor with a focus on MLL1 and core WRAD complex members 
(Fig. 5A). MLL1, but not other WRAD complex associated methyltransferases, is specifically reliant on the WDR5 WIN site for activity (Alicea-Velazquez et al., 2016; Li et al., 2016). As expected, MLL1 was displaced from the WRAD complex upon C16 treatment (Tian et al., 2020); however, in contrast to what was found in AML cells (Tian et al., 2020), the interaction between RBBP5 and WDR5 was also reduced (Fig. 5B,C, S. Fig. 5A). Concomitant with MLL1 dissociation from the WRAD complex, we observed a global reduction in H3K4me3 (Fig. 5D), corresponding to a trend of decreased RNA quantity (S. Fig. 5B). Based on these changes, we utilized chromatin immunoprecipitation-PCR (ChIP-PCR) to investigate changes in H3K4me3 at specific gene promoters and found a reduction in $\mathrm{H} 3 \mathrm{~K} 4 \mathrm{me} 3$ enrichment at the SOX2, MYC, ACTB, and RPL30 promoters (Fig. 5E, S. Fig. 5C). Thus, C16 reduced H3K4 trimethylation globally including at the promoters of key transcription factors important for the CSC state. Taken together, our findings demonstrate the importance of the WRAD complex for CSC maintenance and provide data that this complex represents a small molecule target to neutralize the CSC state. 


\section{Discussion}

Our findings demonstrate that the GBM CSC phenotype is reliant on the WRAD complex for epigenetic maintenance as compared to non-stem tumor cells and non-malignant neural populations. We provide the first evidence for the role of WDR5 in regulating the GBM CSC state, which is consistent with our previous observations of the importance of RBBP5 for GBM CSC self-renewal (Alvarado et al., 2017). Moreover, our findings are consistent with previous observations of the importance of MLL1 in GBM CSCs (Gallo et al., 2013; Heddleston et al., 2012). Identifying mechanisms to attenuate the CSC state remains an immediate priority for malignant cancers, including GBM, and it is well established that self-renewal is driven by a core set of master transcription factors (Mehta et al., 2011; Rheinbay et al., 2013; Suva et al., 2014). There have been recent promising efforts to target these transcription factors, such as with the OLIG2 inhibitor CT-129 (Oasa et al., 2020), but DNA/protein interactions have been historically difficult to target (Bushweller, 2019). Therefore, understanding the upstream molecular network of these core pluripotency transcription factors may provide more rational therapeutic targets.

Tumor cells in a variety of cancers have shown dependence on the WRAD complex for survival, including in leukemia, pancreatic cancer, breast cancer, and ovarian cancer (reviewed in (Aho et al., 2019b; Lu et al., 2018; Zhao et al., 2021). The role of the complex and individual members appears to vary in different cancers, likely due to the array of WDR5 interaction partners that have been identified (Guarnaccia et al., 2021). Likewise, WIN site inhibitors appear to have different mechanisms of action across tumor types. Perhaps the best studied WRAD complex interaction is in MLL-rearranged AML, where one WIN site inhibitor led to global H3K4me2/3 reduction (Zhang et al., 2018), while another led to H3K4me3 reduction specifically on HOX genes (Cao et al., 2014). Yet another report found that WDR5 WIN site inhibitors led to potent induction of apoptosis in MLL1-rearranged AML by obstructing protein synthesis capacity, independently of 
changes in histone methylation (Aho et al., 2019a). Together, these data suggest a context- and tumor-type specific role of the WRAD complex, likely underlain by differences in expression and function of binding partners, available chromatin binding sites, and downstream signaling networks. Given this versatile nature of the WRAD complex and its members across cancer, a more focused assessment in each cancer, including GBM, is warranted. It remains unclear exactly how C16, the WIN site inhibitor tested in the current study, leads to cell death; this represents an immediate future direction as it may also provide insight into putative therapeutic resistance mechanisms.

Our data provide proof of concept for developing WRAD inhibitors based on an unbiased screen, genetic loss-of-function studies on WDR5, and the use of a tool compound, C16. A current limitation is the limited brain penetration of $\mathrm{C} 16$, which provides a clear need for medicinal chemistry efforts to surmount challenges within the current existing scaffolds (such as poor permeability and potential transporter efflux) and turns attention to inhibitor modifications that will lead to overall improved brain penetration. Our transformed neural stem cell models suggest the existence of a therapeutic window to target WDR5 in CSCs without compromising normal neural function, and future drug developments must take care to maintain this window. Taken together, our findings provide the first report linking WDR5 to the GBM CSC phenotype, highlight a key role for the WRAD complex in the epigenetic maintenance of the CSC state, and provide a starting point for WRAD complex inhibitors to neutralize CSC populations in GBM and potentially other advanced cancers. 


\section{Acknowledgements}

We thank members of the Stauffer, Hubert, and Lathia laboratories for critical feedback. We also thank Ms. Amanda Mendelsohn for illustration assistance. This work was supported by National Institutes of Health (NIH) T32CA059366 and NIH F32NS116109 to K.M.; NIH F30CA250254 to A.J.L.; NIH/NCATS CTSA KL2TR0002547, the Clinical Translational Science Collaborative of Cleveland grant UL1TR002548, an American Brain Tumor Association Discovery Grant in memory of Dr. Joseph Weiss, grant \#IRG-16-186-21 to the Case Comprehensive Cancer Center from the American Cancer Society, and support from the VeloSano Cancer Research Fund to C.G.H.; R35 CA197718 to J.N.R.; and the Lerner Research Institute and Case Comprehensive Cancer Center to J.D.L. Work in the Lathia laboratory is also supported by NIH grants P01 CA245705, R01 NS109742, and R01 NS117104. S.R.S thanks the Lerner Research Institute for lab startup support and Cleveland Clinic Philanthropy and an anonymous donor for a generous donation to support capital purchases for this research. We thank the Vanderbilt University Medical Center Metabolic Physiology Shared Resource Core and the Diabetes Research and Training Center for in-life brain plasma studies using compound C16. The Metabolic Physiology Shared Resource is supported by NIH grant DK020593.

\section{Author Contributions}

K.M., C.G.H., J.D.L., S.R.S., J.N.R. \& J.A. designed the study and experiments; K.M., S.S., D.J.S., C.M.G., L.W., G.R., R.S., K.K., C.G.H., A.L., J.D.K., A.K., S.J. \& J.A. performed experiments and analyzed data; T.E.M. provided guidance on the organoid screen; K.M., C.G.H., J.D.L., S.R.S. \& E.E.M-H. wrote the manuscript. All authors approved the final version of the manuscript.

\section{Declaration of interests}

The authors do not have any competing interest to declare. 


\section{Figure Legends}

Figure 1: Spatial functional genomics screening defines genes essential in cancer niches. (A-C) SOX2 IHC shows enrichment of SOX2+ cells in the GBM organoid rim. (D) Cells from the organoid rim display a higher frequency of stem cell behavior (sphere formation) by limiting dilution assay. Error bars represent 95\% confidence intervals for stem cell frequency. Chi-squared p-value for difference in sphere formation is shown. (E-J) Organoids were infected with an shRNA library targeting epigenetic modifiers (mVenus) and stained with CellTracker CMAC blue dye to label the entire outer rim region. Live confocal imaging of screened GBM528 organoids was used to verify proper spatial labeling prior to subsequent dissociation. Z-stacks showing labeling intensity (pseudocolored) (E-F) and individual image slices showing labeling overlap (G-I) are shown using a 20X objective. Subsequently, (J) single cells were isolated from the organoids and separated into rim or core populations by FACS, and then DNA was isolated for barcode sequencing and analysis. (K) Rank ordered list of genes targeted in the shRNA screen, ranked by depletion of the shRNA as detected by sequencing in the SOX2-enriched niche. Dotted line represents $p=0.05$ as determined by RIGER analysis of all hairpin sequences and replicates. Niche-specific hits are color coded, and common hits (including RPA3 positive control) are shown in black. (L) Venn diagram of screen hits showing localization in SOX2-enriched or SOX2depleted niches or common to both regions.

Figure 2: WDR5 knockdown reduces GBM CSC growth, self-renewal and tumor initiation. (A) Immunoprecipitation of RBBP5 (left) and WDR5 (right) in 4 GBM CSC models. Immunoblotting was performed for WRAD complex members and the WRAD-associated methyltransferase MLL1. (B) Short hairpin RNA-mediated targeting of WDR5 was done with 2 non-overlapping short hairpins in 3 CSC models, DI318, 3832 and L0. Western blots indicate the level of WDR5 protein in CSCs infected with a non-targeting (shNT) control virus or WDR5 knockdown (KD) viruses. (C) 
Proliferation of WDR5 KD and shNT control CSCs over 7 days, determined by Incucyte live cell imaging. Values represent mean fold change in cell count relative to Day $0,+/$ - standard deviation (SD), $n=3$ biological replicates, $p$ values determined by two-tailed unpaired t tests (D) WDR5 KD and shNT control CSCs were plated, and viable cell counts were measured by CellTiter Glo luminescence viability assay after 3 days. Bars represent mean luminescence values relative to the average for shNT control cells, +/- SD, circles represent biological replicates, $p$ values determined by one way ANOVA and post-hoc Dunnett's multiple comparisons test. (E) In vitro limiting-dilution analysis was performed on WDR5 KD and shNT control CSCs. Bars represent sphere formation frequency from one representative experiment; error bars represent $95 \%$ confidence intervals for stem cell frequency. Mean sphere formation frequency for each group is listed in the table on the right. Independent biological replicates are shown in S. Fig. 2C. (F) Kaplan-Meier survival plot of mice intracranially implanted with WDR5 KD or shNT control CSCs. $\mathrm{p}$ values indicate comparisons between shNT and shWDR5 and were determined by log-rank analysis.

Figure 3: A WDR5 small molecule inhibitor reduces GBM CSC viability, growth and selfrenewal. (A) Structure of C16 (B) GBM CSCs (top) and CB660 transformed human neural stem cells (bottom) were treated with a range of concentrations of C16, a small molecule inhibitor of WDR5. After 7 days, viable cell counts were measured by CellTiter Glo viability assay. Values represent mean luminescence values normalized to DMSO-treated cells. One representative curve per cell model is shown. (C) Proliferation of C16-treated CSCs over 10 days, determined by IncuCyte live cell imaging. Values represent mean fold change in cell count relative to Day 0 , +/- SD, $n=3$ technical replicates; one representative experiment is shown per CSC model. (D) GBM CSCs were treated with a range of concentrations of C16 and subjected to Caspase 3/7 Glo luminescence assay to measure caspase 3/7 activity. Bars represent fold change in caspase 3/7 activity per cell relative to the average for DMSO-treated cells, +/- SD; circles represent 
biological replicates. $\mathrm{p}$ values determined by one way ANOVA and post-hoc Dunnett's multiple comparisons test. (E) In vitro limiting-dilution analysis was performed on CSCs in the presence of C16. Bars represent mean sphere formation frequency, +/- SD; symbols represent biological replicates. A table with mean sphere formation frequency per group is shown in Supplemental Figure 3E. (F) IHC staining of phospho-histone $\mathrm{H} 3(\mathrm{pH}-\mathrm{H} 3)$ in 4 independent $\mathrm{C} 16$-treated (10 $\mu$ M) GBM organoids at 10X magnification. (G) A total of 500,000 DI318 CSCs were implanted into the flanks of mice, and once tumors developed, $3 \mathrm{mg} / \mathrm{kg} \mathrm{C} 16$ was injected into the tumors daily. Tumor volume over time normalized to tumor size at Day 0 (left) is shown. p values determined by two-tailed, unpaired t test comparing means per group at each time point. (H) A total of 500,000 LO CSCs were implanted into the flanks of mice, and once tumors developed, 10 $\mathrm{mg} / \mathrm{kg} \mathrm{C16}$ was injected intraperitoneally daily. Tumor volume over time normalized to tumor size at Day 0 (left) is shown. $\mathrm{p}$ values determined by two-tailed, unpaired t test comparing means per group at each time point.

Figure 4: A WDR5 small molecule inhibitor diminishes SOX2/OCT4 expressing CSCs. (A) Schematic describing the SORE6-GFP lentiviral reporter system. The SOX2 and OCT4 promoter response elements (cloned from the NANOG promoter) are fused to a destabilized GFP. (B-D) GBM CSC models transduced with the SORE6-GFP reporter were treated with the C16 WDR5 inhibitor. (B) Representative images Day 7 post treatment are shown. (C) GFP+ cell numbers were quantified over 10 days using IncuCyte live cell imaging. One representative time course experiment is shown for each CSC model. Average GFP+ cell count per image is plotted at each time point, +/- SEM per image. Multiple images were taken per well with $n=3$ technical replicates (wells). (D) GFP+ cell numbers at Day 7 after treatment with $5 \mu \mathrm{M}$ C16. Each line represents a biological replicate. $\mathrm{p}$ values determined by two-tailed paired t-tests. 
Figure 5: WDR5 inhibitor reduces the interaction between WDR5 and WRAD complex members and diminishes the H3K4me3 mark. (A) Model of the WRAD complex indicating points of protein-protein interactions, based on structures solved in (Xue et al., 2019). (B) Immunoprecipitation of RBBP5 after C16 inhibitor treatment ( $5 \mu \mathrm{M}, 1$ day) in 2 GBM CSC models. Immunoblotting was performed for WRAD complex members and the WRAD-associated methyltransferase MLL1. Representative experiments are shown. (C) Quantification of WDR5 (left) and MLL1 (right) immunoprecipitated by RBBP5, relative to actin quantity from each sample's input. Circles represent biological replicates. (D) Left: Western blots showing histone 3 lysine 4 trimethylation ( $\mathrm{H} 3 \mathrm{~K} 4 \mathrm{me}$ ) levels in whole cell lysates after $\mathrm{C} 16$ treatment $(5 \mu \mathrm{M}, 3$ days) in 3 CSC models. Representative experiments are shown. Right: Quantification of H3K4me3, relative to $\mathrm{H} 3$ quantity after $\mathrm{C} 16$ treatment $(5 \mu \mathrm{M}, 3$ days) in 3 CSC models. Circles represent biological replicates; lines connect DMSO- and C16-treated specimens from the same experiment. (E) Chromatin immunoprecipitation of $\mathrm{H} 3 \mathrm{~K} 4 \mathrm{me} 3$ was performed after $\mathrm{C} 16$ treatment ( $5 \mu \mathrm{M}, 3$ days). PCR was performed on immunoprecipitated DNA using primers designed at the promoter regions of the indicated genes. Symbols represent quantity as a percent of total ChIP input normalized to \% input for $\mathrm{H} 3$ pulldown for each gene. Lines connect DMSO- and C16-treated specimens from the same experiment. 


\section{Tables Legends}

Table 1: IC50 values of WDR5 inhibitors on GBM CSC models and control cell types. Cells were treated with a range of concentrations of the peptide WDR5 inhibitor MM-102 and small molecule WDR5 inhibitors Piribedil and OICR9429. After 7 days, viable cell counts were measured by CellTiter Glo viability assay. Values represent mean IC $_{50}$ values (relative to DMSOtreated cells) across multiple experiments; number of independent replicates is indicated in the table.

\begin{tabular}{|c|c|c|c|c|c|}
\hline & Cell type & $\begin{array}{l}\text { Average } \\
\text { IC50 } \\
\text { MM-102 }\end{array}$ & $\begin{array}{l}\text { Average } \\
\text { IC50 } \\
\text { Piribedil }\end{array}$ & $\begin{array}{c}\text { Average } \\
\text { IC50 } \\
\text { OICR9429 }\end{array}$ & $\begin{array}{c}\text { Average } \\
\text { IC50 } \\
\text { C16 }\end{array}$ \\
\hline \multirow{12}{*}{$\begin{array}{c}\text { GBM } \\
\text { CSCs }\end{array}$} & 3832 & $\begin{array}{c}44 \mu \mathrm{M} \\
(\mathrm{n}=2)\end{array}$ & $\begin{array}{c}>20 \mu \mathrm{M} \\
(\mathrm{n}=1)\end{array}$ & $\begin{array}{c}>20 \mu \mathrm{M} \\
(\mathrm{n}=1)\end{array}$ & $\begin{array}{c}2.4 \mu \mathrm{M} \\
(\mathrm{n}=6)\end{array}$ \\
\hline & DI-318 & $\begin{array}{c}49 \mu \mathrm{M} \\
(\mathrm{n}=2)\end{array}$ & & & $\begin{array}{c}2.9 \mu \mathrm{M} \\
(\mathrm{n}=5)\end{array}$ \\
\hline & 4121 & & $\begin{array}{c}>20 \mu \mathrm{M} \\
(\mathrm{n}=1)\end{array}$ & $\begin{array}{c}>20 \mu \mathrm{M} \\
(\mathrm{n}=1)\end{array}$ & $\begin{array}{c}3.5 \mu \mathrm{M} \\
(\mathrm{n}=2)\end{array}$ \\
\hline & 387 & & & & $\begin{array}{c}2.6 \mu \mathrm{M} \\
(\mathrm{n}=3)\end{array}$ \\
\hline & 3691 & & & & $\begin{array}{c}2.2 \mu \mathrm{M} \\
(\mathrm{n}=2)\end{array}$ \\
\hline & LO & $\begin{array}{c}35 \mu \mathrm{M} \\
(\mathrm{n}=3)\end{array}$ & & & $\begin{array}{c}0.4 \mu \mathrm{M} \\
(\mathrm{n}=9)\end{array}$ \\
\hline & L1 & & & & $\begin{array}{c}4.4 \mu M \\
(n=2)\end{array}$ \\
\hline & L2 & & & & $\begin{array}{c}1.3 \mu M \\
(n=2)\end{array}$ \\
\hline & GBM23 & & & & $\begin{array}{c}0.95 \mu \mathrm{M} \\
(\mathrm{n}=4)\end{array}$ \\
\hline & GBM528 & & & & $\begin{array}{c}6.6 \mu \mathrm{M} \\
(\mathrm{n}=2)\end{array}$ \\
\hline & HSJD-pGBM-001 & & & & $\begin{array}{c}2.3 \mu \mathrm{M} \\
(\mathrm{n}=2)\end{array}$ \\
\hline & BT124 & & & & $\begin{array}{c}1.8 \mu \mathrm{M} \\
(\mathrm{n}=2)\end{array}$ \\
\hline & HSJD-DIPG-007 & & & & $\begin{array}{c}2.9 \mu \mathrm{M} \\
(\mathrm{n}=2)\end{array}$ \\
\hline
\end{tabular}


bioRxiv preprint doi: https://doi.org/10.1101/2021.09.20.461125; this version posted September 23, 2021. The copyright holder for this preprint (which was not certified by peer review) is the author/funder, who has granted bioRxiv a license to display the preprint in perpetuity. It is made available under aCC-BY-NC-ND 4.0 International license.

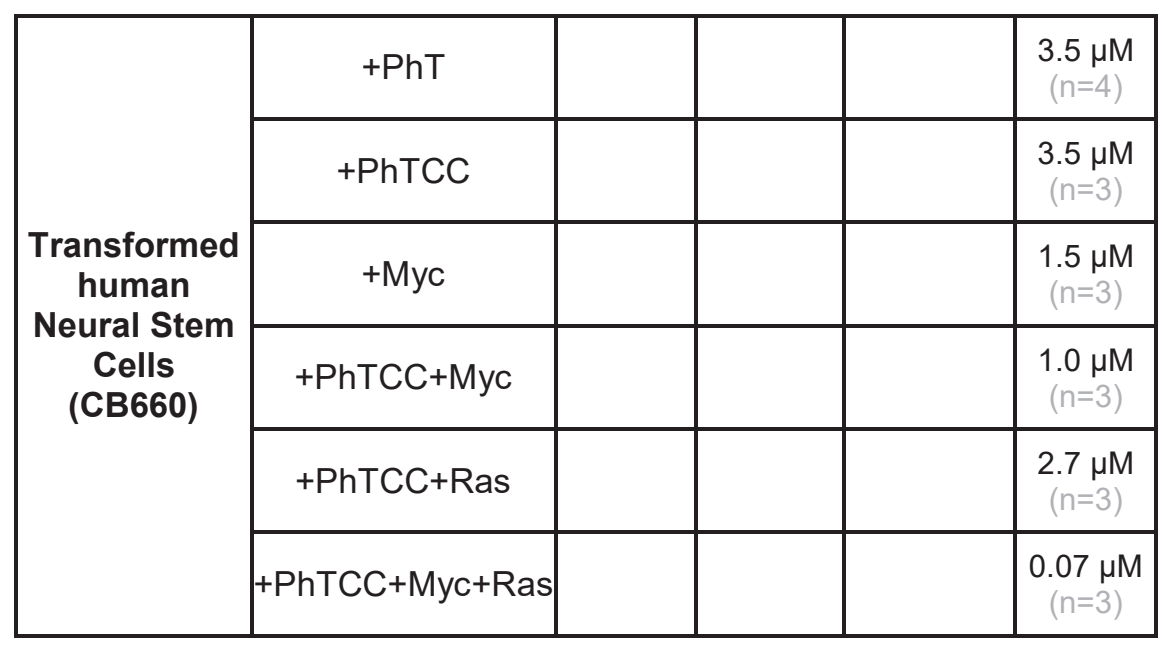




\section{STAR Methods}

\section{RESOURCE AVAILABILITY}

\section{Lead contact}

Further information and requests for resources and reagents should be directed to and will be fulfilled by the lead contact, Justin D. Lathia (lathiaj@ccf.org).

\section{Materials availability}

This study did not generate new unique reagents.

\section{EXPERIMENTAL MODEL AND SUBJECT DETAILS}

\section{Animals}

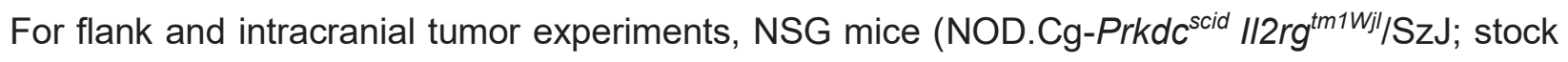
005557; Jackson Laboratory) were bred in house (Cleveland Clinic). For DI318 intracranial tumor experiments, 7.5-week-old NSG mice were used. For DI318 flank tumor experiments, NSG mice at least 8 weeks of age were used. For L0 flank tumor experiments, 8-week-old NSG mice were used. An equal number of male and female mice were used for all animal experiments and were evenly distributed between experimental groups. For the IP dosing weight study, 8-week-old NSG mice were used. For intratumoral dosing, C16 was dissolved at $5.1 \mathrm{mg} / \mathrm{ml}$ in $17.5 \% \mathrm{DMSO}$ in PBS. For intraperitoneal (IP) dosing, C16 was dissolved at $2 \mathrm{mg} / \mathrm{ml}$ in $20 \%$ hydroxypropyl beta cyclodextran $(B C D)$ in ddH2O. The solution was then made acidic with 1.0 equivalent of aq. $1 \mathrm{~N}$ $\mathrm{HCl}$. Mice were housed in the Cleveland Clinic Biological Resources Unit. All experiments were performed in compliance with institutional guidelines and were approved by the Institutional Animal Care and Use Committee of the Cleveland Clinic (protocol 2019-2195). 


\section{Primary cell cultures}

Cancer stem cell (CSC) models were generated by passaging primary tumor cells as GBM xenografts as previous described (Lathia et al., 2010). Briefly, primary tumor cells were intracranially implanted into NSG mice, and upon tumor formation, tumors were isolated, digested with papain (Worthington) as described previously (Alvarado et al., 2017), and dissociated cells were plated overnight in Neurobasal ${ }^{\mathrm{TM}}$ medium minus phenol red (Gibco) with $1 \mathrm{X}$ B-27 supplement (Gibco), $1 \mathrm{mmol} / \mathrm{L}$ sodium pyruvate, $2 \mathrm{mmol} / \mathrm{L}$ L-glutamine, $50 \mathrm{U} / \mathrm{mL}$ penicillin/streptomycin, $20 \mathrm{ng} / \mathrm{ml}$ human (h)EGF and $20 \mathrm{ng} / \mathrm{ml} \mathrm{hFGF}$ (R\&D systems). Subsequently, CD133+ cells were isolated by magnetic bead sorting (Miltenyi). CD133+ cells were cultured in the media described above. Some cell models were previously established at other institutions (Table 1). CD133+ cells were seeded in suspension culture at $5 \times 10^{4}$ cells $/ \mathrm{ml}$ and passaged no more than 10 times. After 10 passages, cells were re-implanted into NSG mice and enriched for CD133+ cells.

Organoids were formed as previously described (Hubert et al., 2016) by suspending tumor cells in $80 \%$ Matrigel (BD Biosciences) and forming $20 \mu \mathrm{l}$ pearls on parafilm molds prior to culture. Organoids were seeded with 10,000 cells per organoid and cultured in 6-well or 10-cm plates with shaking in supplemented Neurobasal media as above with the addition of phenol red. Transformed human neural stem cells (CB660) were generated as previously described (Hubert et al., 2013). These include NSC-CB660 cells with dominant-negative p53DD and hTERT (PhT); NSC-CB660 cells with dominant-negative $\mathrm{p53}{ }^{\mathrm{DD}}, \mathrm{hTERT}$, CyclinD1 and CDK4 ${ }^{\mathrm{R} 24 \mathrm{C}}$ (PhTCC); NSCCB660 + PhTCC + Myc; NSC-CB660 + PhTCC + H-RasV12; and NSC-CB660 + PhTCC + Myc $+\mathrm{H}-\mathrm{Ras} V 12$. These lines were grown adherently on plates coated with $10 \mu \mathrm{g} / \mathrm{ml}$ laminin (Sigma) and cultured in a 1:1 ratio of DMEM-F12 and NeuroCult NS-A Basal Medium (Human) (Stem Cell Technologies) with 1 X N-2 supplement (Gibco), 1X B-27 supplement, sodium pyruvate, Lglutamine, $1 \mathrm{X}$ pen/strep, $20 \mathrm{ng} / \mathrm{ml}$ human (h)EGF and $20 \mathrm{ng} / \mathrm{ml} \mathrm{hFGF} 2$. Cells were grown at $37^{\circ} \mathrm{C}$ 
with $5 \%$ CO2. The sex of the cells is as follows: 3832 (female), DI318 (male). The sex of other GBM models is not known. De-identified GBM specimens were collected from the Cleveland Clinic Brain Tumor and Neuro-Oncology Center in accordance with an Institutional Review Boardapproved protocol, and informed consent was obtained from all GBM patients contributing tumor specimens.

\section{METHOD DETAILS}

\section{Organoid screen}

To investigate the effects of targeting epigenetic regulators in glioblastoma cells within the tumor microenvironment, we used an inducible RNAi screening system that was previously used for screening in vivo (Miller et al., 2017). Our shRNA library contained 1,586 shRNAs targeting 406 known chromatin and transcriptional regulator genes (2-4 shRNAs per gene), with positive and negative control shRNAs. GBM528 patient-derived CSCs were transduced with the shRNA library pool at low $\mathrm{MOI}$ to ensure single viral integration, and cells with genomic integration of shRNAs as monitored by expression of a constitutive mVenus fluorescent reporter were selected using FACS. Cells were allowed to recover and expand for three passages.

Organoids for shRNA screening were formed as described above by seeding 30,000 positively infected cells per $20 \mu \mathrm{l}$ organoid using custom 96-well-format parafilm molds and multichannel pipettes. Organoids were allowed to grow and mature uninduced for 1 month in $500 \mathrm{ml}$ spinner flasks (Corning \#3578) in $250 \mathrm{~mL}$ of media at $37^{\circ} \mathrm{C}$ with $5 \% \mathrm{CO}$, prior to the addition of doxycycline $(1 \mu \mathrm{g} / \mathrm{ml}$, Sigma-Aldrich) to induce gene knockdown. Organoids were maintained on doxycycline for 21 days. Each of 3 organoid screen cohorts, consisting of 55 independent organoids each, were processed and analyzed separately. This represents an approximate 1000fold library coverage for each screen replicate. Day 0 controls were also collected, stored frozen, 
and processed in parallel for comparison. At the end of the screen, organoids were regionally labeled with CellTracker CMAC (Molecular Probes) for 2 hours as previously described (Shakya et al., 2021), and single organoids from each screen cohort were spot-checked by confocal microscopy in a compatible dish (MatTek 35 mm glass bottom dish P35G-1.5-10-C) to ensure proper CMAC labeling. Labeled organoids were dissociated and separated by FACS sorting, marked by positivity for constitutive mVenus expression and doxycycline-induced dsRed expression, and sorted into regional populations based upon retention of CMAC regional blue dye.

Genomic DNA was isolated from each screened population and sequenced as described (Miller Nature 2017). Genomic DNA was isolated by two rounds of phenol extraction using PhaseLock tubes (5prime) followed by isopropanol precipitation. Deep sequencing libraries were generated by PCR amplification of shRNA guide strands using barcoded primers that tag the product with standard Illumina adapters (p7+loop, 5'-CAAGCAGAAGACGGCATACGA-NNNN (4 nucleotide barcode)-TAGTGAAGCCACAGATGTA-3'; p5+miR3', 5'AATGATACGGCGACCACCGATGGATGTGGAATGTGTGCGAGG-3'). Libraries were sequenced on the HiSeq 2500 platform at the Cleveland Clinic Genomics Core Facility. Libraries were sequenced using a primer that reads in reverse into the guide strand (miR30EcoRISeq, 5'TAGCCCCTTGAATTCCGAGGCAGTAGGCA-3'). Sequence processing was performed as previously described using two custom workflows at https://usegalaxy.org. Raw read counts were converted to reads per million (RPM) to control for variations in total shRNA reads in each sample. shRNAs were scored using RIGER and extension of the GENE-E package (Broad Institute) (Luo et al., 2008). Median RPM value for each replicate was used for analysis. The signal-to-noise ratio of replicates was used to calculate individual shRNA score based on their ability to deplete cells in the induced cohorts compared to the control inputs, and second-best shRNA score was 
used to rank genes. Expressed genes with a total RIGER p-value score $<0.05$ for depletion compared to controls were considered hits.

\section{Organoid IHC for SOX2/pHH3}

Organoids were treated with drugs as indicated while shaking in 6-well plates. Treated organoids were then fixed in $10 \%$ neutral buffered formalin for at least 24 hours prior to transfer to $70 \%$ ethanol and subsequent paraffin embedding by the LRI Biomedical Engineering histology core. Sections $(4 \mu \mathrm{m})$ were cut, placed on slides, deparaffinized, unmasked by boiling in $1 \mathrm{X}$ citrate solution (Cell Signaling) and blocked with normal donkey serum or BSA. Antigens were detected using anti-SOX2 (R\&D, \#AF2018) and anti-phospho-Histone H3 (Cell Signaling, \#9701S) antibodies. Detection was performed with DAB and counterstained with Gills 2 Hematoxylin and bluing reagent. Coverslips were mounted with Permount, and whole slides were scanned on a Leica Aperio AT2 digital slide scanner using a 20X objective in the LRI imaging core. Image fields were extracted using Leica ImageScope software.

\section{Chemical synthesis \& WDR5 TR-FRET competition assay}

Compound 16 was synthesized as previously published (Tian et al., 2020). Recombinant His6SUMO-WDR5 was expressed and purified as previously published (Tian et al., 2020). The WDR5 TR-FRET Competition Assay was run following previously published methods (Tian et al., 2020). Compound 16 was tested for MLL1-FITC probe displacement using a 10-point CRC with a top concentration of $10 \mu \mathrm{M}$ and 5-fold dilution scheme. The 520/495 FRET ratio was plotted against compound concentration and fit with a "One Site - Fit Ki" in PRISM 8, with "HotNM" constrained to $150 \mathrm{nM}$ and the "HotKdNM" constrained to $2 \mathrm{nM}$. Compound 16 was tested in three independent experiments with duplicates run for each experiment ( $n=6$ total). 


\section{BBB penetration potential using MDR1-MDCK cell monolayers}

MDR1-MDCK cell monolayers were grown to confluence on collagen-coated microporous membranes in 12-well assay plates. The permeability assay buffer was Hanks' balanced salt solution containing $10 \mathrm{mM}$ HEPES and $15 \mathrm{mM}$ glucose at a $\mathrm{pH}$ of 7.4 . The buffer in the receiver chamber also contained $1 \%$ bovine serum albumin. The dosing solution concentration was $5 \mu \mathrm{M}$ of test article in the assay buffer. Cell monolayers were dosed on the apical side (A-to-B) or basolateral side (B-to-A) and incubated at $37^{\circ} \mathrm{C}$ with $5 \% \mathrm{CO}_{2}$ in a humidified incubator. Samples were taken from the donor and receiver chambers at 120 minutes. Each determination was performed in duplicate. All samples were assayed by LC-MS/MS using electrospray ionization. Further details can be found at Absorption.com, assay \#EA203.

\section{In vivo brain:plasma study in mice}

C16 was formulated from powder as $2 \mathrm{mg} / \mathrm{mL}$ solution in a 20\% 2-(hydroxypropyl)- $\beta$-cyclodextrin in $\mathrm{ddH}_{2} \mathrm{O}$ (HP- $\beta-C D$; Sigma, catalogue no. C0926-10G) solution. The solution was then made acidic with 1.0 equivalent of aq. $1 \mathrm{~N} \mathrm{HCl}$. The mixture was vortexed briefly and then sonicated for $5 \mathrm{~min}$ in a room temperature water bath sonicator to afford a clear solution to fine microsuspension. Animals were injected with a maximal dosing volume of $5 \mathrm{~mL} / \mathrm{kg}$ to give a final $10 \mathrm{mg} / \mathrm{kg}$ body weight dose.

Male CD-1 mice (Charles River Laboratories, Wilmington, MA) were maintained on a regular rodent chow. Animals were housed 4 per cage and maintained on a 12-hour light cycle (06001800). Room temperature was monitored daily and maintained at $22-25^{\circ} \mathrm{C}$. Mice were overnight fasted on the evening prior to study (food removed between 1500-1600 h). On the morning of study mice were weighed and allowed to acclimate to the room for at least 30 min prior to dosing. Food was returned $3 \mathrm{~h}$ after injection. At time 0 an IP injection of the test article was given. At 0.5 $\mathrm{h}, 1 \mathrm{~h}, 3 \mathrm{~h}$, and $6 \mathrm{~h}$ after injection ( $\mathrm{n}=2$ per time point), mice were placed into a plane of anesthesia 
using Isoflurane. A terminal blood sample was collected via cardiac puncture followed by immediate euthanasia and brain collection. Brain was washed with cold PBS or Saline, blotted dry on a piece of gauze, weighed, and flash frozen in liquid Nitrogen. Whole blood was centrifuged at 5000-6000 rcf for 5 minutes and plasma was removed into a fresh tube for storage. All samples were stored at $-80^{\circ} \mathrm{C}$ until shipment on dry ice to Q2 Solutions for tissue distribution bioanalysis (Q2 Solutions Bioanalytical and ADME Laboratories, Indianapolis, IN). The plotted time-course exposure plot for $\mathrm{C} 16$ represents the average concentrations of processed brain and plasma samples (brain homogenate supernatant and plasma) as determined by LC-MS/MS.

\section{Western blotting \& co-immunoprecipitation}

For protein isolation, cells were washed out of medium with PBS. Lysates were prepared using modified radioimmunoprecipitation assay (RIPA) buffer containing protease and phosphatase inhibitors (50 mM Tris-HCl, pH 7.4, 1\% NP-40 (vol/vol), 0.25\% Na-deoxycholate (wt/vol), $150 \mathrm{mM}$ $\mathrm{NaCl}, 1 \mathrm{mM}$ EDTA, 1X Sigma p8340 Protease Inhibitor Cocktail, Sigma p5726 Phosphatase Inhibitor Cocktail, $1 \mathrm{mM} \mathrm{NaF,} 1 \mathrm{mM}$ PMSF). Cells were lysed for $30 \mathrm{~min}$ on ice and centrifuged at maximum speed in a tabletop centrifuge to remove debris. Protein concentration was measured on a spectrophotometer (read at $595 \mathrm{~nm}$ ) using Bradford reagent (500-0006; Bio-Rad). SDSPAGE was performed, and cell lysates were resolved on polyacrylamide gels. Proteins were transferred onto PVDF membranes and blocked with TBST+5\% BSA. A ChemiDoc MP imaging system (Bio-Rad) was used for visualization. For co-immunoprecipitation experiments, lysates were prepared as described above. Protein lysate $(500 \mu \mathrm{g})$ was incubated with $5 \mu \mathrm{g}$ immunoprecipitation antibody at $4^{\circ} \mathrm{C}$ overnight with rotation followed by incubated with protein A/G agarose beads for 1 hour at $4^{\circ} \mathrm{C}$ with rotation. Beads were washed 5 times with RIPA buffer, and bead-bound proteins were isolated by boiling antibody-bead complexes in SDS sample buffer. Immunoblotting was performed as described above. For C16 treatment western blots and 
co-immunoprecipitation, cells were plated at $5 \times 10^{5}$ cells $/ \mathrm{ml}$ with thr indicated concentrations of inhibitor.

\section{WDR5 knockdown}

MISSION® pLKO.1-puro Non-Mammalian shRNA (SHC002) and WDR5 knockdown plasmids were purchased from Sigma. Several clones were tested, and 2 non-overlapping clones with efficient knockdown were selected to produce lentiviral particles (TRC clone IDs: TRCN0000157812 (shWDR5\#12) and TRCN0000118047 (shWDR5\#47)). For virus production, pLKO.1-shRNA plasmids were transfected into 293T cells along with psPAX and pMD2.G packaging plasmids to produce lentivirus. Forty-eight and 72 hours after transfection, supernatant containing lentiviral particles was collected and concentrated with PEGit virus precipitation solution according to manufacturer's protocol (System Biosciences). CSCs were plated on Geltrex, and virus was added to culture medium ( $\mathrm{MOI}=2$ ), and then selected with $2-4 \mu \mathrm{g} / \mathrm{ml}$ puromycin.

\section{$\mathrm{IC}_{50}$, cell growth, viability, apoptosis}

Inhibitors were reconstituted to $10 \mathrm{mM}$ in DMSO. For $\mathrm{IC}_{50}$ determination, cells were plated at 20,000 cells/ml in Geltrex-coated 96-well plates (to promote adherence) and treated with a 9 point, 2- or 3-fold serial dilution of inhibitor. For $\mathrm{IC}_{50}$ calculations, normalization was performed relative to the DMSO condition (100\%) and a well with no cells (0\%). After 7 days, cell viability was determined by ATP quantification with the CellTiter-Glo® Luminescent Cell Viability Assay (Promega). For cell growth assays, cells were plated at 20,000 cells/ml in Geltrex-coated 96-well plates and treated with different doses of inhibitor, then imaged using the IncuCyte Live Cell Analysis System using the cell-by-cell module (Sartorius). For apoptosis assays, cells were plated in duplicate at 20,000 cells/ml in Geltrex-coated 96-well plates and treated with different doses of inhibitor. Caspase 3/7 activity was determined with the Caspase-Glo 3/7 assay (Promega), and 
caspase activity was normalized to cell number by performing the CellTiter Glo Luminescent Cell Viability Assay on the duplicate plate. For quantification of apoptosis over time, cells were plated at 20,000 cells $/ \mathrm{ml}$ in Geltrex-coated 96 -well plates and treated with different doses of inhibitor in the presence of 1:1000 IncuCyte ${ }^{\circledR}$ Caspase-3/7 Dye for Apoptosis (Sartorius).

\section{Limiting dilution analysis}

Cells were plated at 100 cells per well in 12 wells of a 96 -well plate, and two-fold serial dilutions were performed. Twelve wells of each cell dose were plated. Limiting-dilution plots and stem-cell $\begin{array}{lllll}\text { frequencies } & \text { were } & \text { calculated } & \text { analysis }\end{array}$ (http://bioinf.wehi.edu.au/software/elda/index.html; (Hu and Smyth, 2009)). For LDAs with C16 treatment, cells were incubated with inhibitor for the duration of the experiment.

\section{Intracranial implantation}

Intracranial tumor transplants were performed as described previously (Bayik et al., 2020). NSG mice were anesthetized with inhaled isoflurane for the duration of the procedure. A total of 10,000 DI318 CSCs infected with control or WDR5 shRNAs were suspended in $10 \mu$ l Neurobasal null medium and stereotactically implanted in the left hemisphere $\sim 2.5 \mathrm{~mm}$ deep into the brain. Mice were monitored for neurologic signs and weight loss and deemed at endpoint when exhibiting any of these symptoms.

\section{Flank tumor experiments}

NSG mice were transplanted subcutaneously with 500,000 DI318 or L0 human GBM CSCs. After tumor formation (2.5 weeks for DI318, 10 weeks for L0), 3 mg/kg C16 was injected daily directly into the tumors or $10 \mathrm{mg} / \mathrm{kg} \mathrm{C16}$ was injected daily intraperitoneally. When any animals in the experiment reached endpoint (determined by tumor size), mice were euthanized. 


\section{SORE6-GFP reporter experiments}

For SORE6-GFP reporter experiments (SOX2/OCT4 promoter response elements tagged to destabilized GFP), SORE6-dsCopGFP lentiviral particles were generated by transfection of 293T cells. 293T cells were transfected (Fugene transfection reagent) with pPACKH1 vectors and SORE6-dsCopGFP plasmid DNA (kindly provided by Wakefield Lab, NIH) according to the manufacturer's protocols (System Biosciences). Viral supernatant was collected at 48 hours, and virus was concentrated with PEG-it Virus Precipitation solution (System Biosciences). SORE6GFP virus was added to CSCs plated on Geltrex. Forty-eight hours after infection, $2-3 \mu \mathrm{g} / \mathrm{ml}$ puromycin was added to cells. After puromycin selection, cells were collected, and GFPhigh (10$20 \%$ brightest) or GFP-negative cells were isolated by fluorescence activated cell sorting. GFPhigh and GFPnegative cells were subjected to limiting dilution analysis as described above, or protein was isolated for western blot. GFPhigh cells were cultured further and used for inhibitor treatment experiments. Fluorescence images were taken with the IncuCyte Live Cell Analysis System (Sartorius).

\section{QUANTIFICATION AND STATISTICAL ANALYSIS}

Western blot quantification was performed using ImageJ (v1.44o, National Institutes of Health). For two group comparisons, P-values were calculated using unpaired or paired two-tailed t tests. For multiple group comparisons, one-way ANOVA with post hoc tests were used as indicated in the figure legends. Log-rank tests were used for survival analysis. GraphPad Prism 9 was used for statistical tests. All in vitro experiments were done in technical triplicates for each experimental group, and multiple independent experiments were performed. To determine the number of mice needed per group for animal experiments, we utilized the Guidelines for the Care and Use of Mammals in Neuroscience and Behavioral Research from the National Research Council to estimate the minimal number necessary to achieve statistical significance $(p<0.05)$ for all tumor growth studies. The number of animals per arm was based upon the following calculation: $=(1+$ 
bioRxiv preprint doi: https://doi.org/10.1101/2021.09.20.461125; this version posted September 23, 2021. The copyright holder for this preprint (which was not certified by peer review) is the author/funder, who has granted bioRxiv a license to display the preprint in perpetuity. It is made available under aCC-BY-NC-ND 4.0 International license.

$2 C)\left(\frac{s}{d}\right)^{2}$, where $n=$ Number of Animals per Experimental Group; $c=9.18$ when $\alpha=0.05$ and 1 $-\beta=0.85$ (Significance level of $5 \%$ with a power of $85 \%) ; s=$ Standard Deviation $(\approx 7$ days); $d=$ Difference to be Detected ( $\geq 10$ days). Thus, $n=10$ animals were used per group, and to control for sexual dimorphism, males and females were treated as separate experimental groups and combined if there were no differences. $n$ represents independent experiments (biological replicates) or individual mice. Statistical details can be found in figure legends. $p<0.05$ was considered statistically significant. *,$p<0.05 ;{ }^{* *}, p<0.01 ;{ }^{* * *}, p<0.001 ;{ }^{* * *} ; p<0.0001$. 


\section{References}

Abdouh, M., Facchino, S., Chatoo, W., Balasingam, V., Ferreira, J., and Bernier, G. (2009). BMI1 sustains human glioblastoma multiforme stem cell renewal. J Neurosci 29, 8884-8896.

Aho, E.R., Wang, J., Gogliotti, R.D., Howard, G.C., Phan, J., Acharya, P., Macdonald, J.D., Cheng, K., Lorey, S.L., Lu, B., et al. (2019a). Displacement of WDR5 from Chromatin by a WIN Site Inhibitor with Picomolar Affinity. Cell Rep 26, 2916-2928 e2913.

Aho, E.R., Weissmiller, A.M., Fesik, S.W., and Tansey, W.P. (2019b). Targeting WDR5: A WINning Anti-Cancer Strategy? Epigenet Insights 12, 2516865719865282.

Alicea-Velazquez, N.L., Shinsky, S.A., Loh, D.M., Lee, J.H., Skalnik, D.G., and Cosgrove, M.S. (2016). Targeted Disruption of the Interaction between WD-40 Repeat Protein 5 (WDR5) and Mixed Lineage Leukemia (MLL)/SET1 Family Proteins Specifically Inhibits MLL1 and SETd1A Methyltransferase Complexes. J Biol Chem 291, 22357-22372.

Alvarado, A.G., Thiagarajan, P.S., Mulkearns-Hubert, E.E., Silver, D.J., Hale, J.S., Alban, T.J., Turaga, S.M., Jarrar, A., Reizes, O., Longworth, M.S., et al. (2017). Glioblastoma Cancer Stem Cells Evade Innate Immune Suppression of Self-Renewal through Reduced TLR4 Expression. Cell Stem Cell 20, 450-461 e454.

Ang, Y.S., Tsai, S.Y., Lee, D.F., Monk, J., Su, J., Ratnakumar, K., Ding, J., Ge, Y., Darr, H., Chang, B., et al. (2011). Wdr5 mediates self-renewal and reprogramming via the embryonic stem cell core transcriptional network. Cell 145, 183-197.

Bayik, D., Zhou, Y., Park, C., Hong, C., Vail, D., Silver, D.J., Lauko, A., Roversi, G., Watson, D.C., Lo, A., et al. (2020). Myeloid-Derived Suppressor Cell Subsets Drive Glioblastoma Growth in a Sex-Specific Manner. Cancer Discov 10, 1210-1225.

Bushweller, J.H. (2019). Targeting transcription factors in cancer - from undruggable to reality. Nat Rev Cancer 19, 611-624.

Cao, F., Townsend, E.C., Karatas, H., Xu, J., Li, L., Lee, S., Liu, L., Chen, Y., Ouillette, P., Zhu, J., et al. (2014). Targeting MLL1 H3K4 methyltransferase activity in mixed-lineage leukemia. Mol Cell 53, 247-261.

Dahlrot, R.H., Dowsett, J., Fosmark, S., Malmstrom, A., Henriksson, R., Boldt, H., de Stricker, K., Sorensen, M.D., Poulsen, H.S., Lysiak, M., et al. (2018). Prognostic value of O-6-methylguanineDNA methyltransferase (MGMT) protein expression in glioblastoma excluding nontumour cells from the analysis. Neuropathol Appl Neurobiol 44, 172-184.

Dou, Y., Milne, T.A., Ruthenburg, A.J., Lee, S., Lee, J.W., Verdine, G.L., Allis, C.D., and Roeder, R.G. (2006). Regulation of MLL1 H3K4 methyltransferase activity by its core components. Nat Struct Mol Biol 13, 713-719.

Flavahan, W.A., Gaskell, E., and Bernstein, B.E. (2017). Epigenetic plasticity and the hallmarks of cancer. Science 357.

Gallo, M., Coutinho, F.J., Vanner, R.J., Gayden, T., Mack, S.C., Murison, A., Remke, M., Li, R., Takayama, N., Desai, K., et al. (2015). MLL5 Orchestrates a Cancer Self-Renewal State by 
Repressing the Histone Variant H3.3 and Globally Reorganizing Chromatin. Cancer Cell 28, 715729.

Gallo, M., Ho, J., Coutinho, F.J., Vanner, R., Lee, L., Head, R., Ling, E.K., Clarke, I.D., and Dirks, P.B. (2013). A tumorigenic MLL-homeobox network in human glioblastoma stem cells. Cancer Res 73, 417-427.

Gangemi, R.M., Griffero, F., Marubbi, D., Perera, M., Capra, M.C., Malatesta, P., Ravetti, G.L., Zona, G.L., Daga, A., and Corte, G. (2009). SOX2 silencing in glioblastoma tumor-initiating cells causes stop of proliferation and loss of tumorigenicity. Stem Cells 27, 40-48.

Guarnaccia, A.D., Rose, K.L., Wang, J., Zhao, B., Popay, T.M., Wang, C.E., Guerrazzi, K., Hill, S., Woodley, C.M., Hansen, T.J., et al. (2021). Impact of WIN site inhibitor on the WDR5 interactome. Cell Rep 34, 108636.

Guarnaccia, A.D., and Tansey, W.P. (2018). Moonlighting with WDR5: A Cellular Multitasker. J Clin Med 7.

Guilhamon, P., Chesnelong, C., Kushida, M.M., Nikolic, A., Singhal, D., MacLeod, G., Madani Tonekaboni, S.A., Cavalli, F.M., Arlidge, C., Rajakulendran, N., et al. (2021). Single-cell chromatin accessibility profiling of glioblastoma identifies an invasive cancer stem cell population associated with lower survival. Elife 10.

Hall, A.W., Battenhouse, A.M., Shivram, H., Morris, A.R., Cowperthwaite, M.C., Shpak, M., and lyer, V.R. (2018). Bivalent Chromatin Domains in Glioblastoma Reveal a Subtype-Specific Signature of Glioma Stem Cells. Cancer Res 78, 2463-2474.

Heddleston, J.M., Wu, Q., Rivera, M., Minhas, S., Lathia, J.D., Sloan, A.E., Iliopoulos, O., Hjelmeland, A.B., and Rich, J.N. (2012). Hypoxia-induced mixed-lineage leukemia 1 regulates glioma stem cell tumorigenic potential. Cell Death Differ 19, 428-439.

Hu, Y., and Smyth, G.K. (2009). ELDA: extreme limiting dilution analysis for comparing depleted and enriched populations in stem cell and other assays. J Immunol Methods 347, 70-78.

Huang, S. (2013). Genetic and non-genetic instability in tumor progression: link between the fitness landscape and the epigenetic landscape of cancer cells. Cancer Metastasis Rev 32, 423448.

Hubert, C.G., Bradley, R.K., Ding, Y., Toledo, C.M., Herman, J., Skutt-Kakaria, K., Girard, E.J., Davison, J., Berndt, J., Corrin, P., et al. (2013). Genome-wide RNAi screens in human brain tumor isolates reveal a novel viability requirement for PHF5A. Genes Dev 27, 1032-1045.

Hubert, C.G., Rivera, M., Spangler, L.C., Wu, Q., Mack, S.C., Prager, B.C., Couce, M., McLendon, R.E., Sloan, A.E., and Rich, J.N. (2016). A Three-Dimensional Organoid Culture System Derived from Human Glioblastomas Recapitulates the Hypoxic Gradients and Cancer Stem Cell Heterogeneity of Tumors Found In Vivo. Cancer Res 76, 2465-2477.

Jacob, F., Salinas, R.D., Zhang, D.Y., Nguyen, P.T.T., Schnoll, J.G., Wong, S.Z.H., Thokala, R., Sheikh, S., Saxena, D., Prokop, S., et al. (2020). A Patient-Derived Glioblastoma Organoid Model and Biobank Recapitulates Inter- and Intra-tumoral Heterogeneity. Cell 180, 188-204 e122. 
Karatas, H., Townsend, E.C., Cao, F., Chen, Y., Bernard, D., Liu, L., Lei, M., Dou, Y., and Wang, S. (2013). High-affinity, small-molecule peptidomimetic inhibitors of MLL1/WDR5 protein-protein interaction. J Am Chem Soc 135, 669-682.

Koshkin, S.A., Anatskaya, O.V., Vinogradov, A.E., Uversky, V.N., Dayhoff, G.W., 2nd, Bystriakova, M.A., Pospelov, V.A., and Tolkunova, E.N. (2021). Isolation and Characterization of Human Colon Adenocarcinoma Stem-Like Cells Based on the Endogenous Expression of the Stem Markers. Int J Mol Sci 22.

Lathia, J.D., Gallagher, J., Heddleston, J.M., Wang, J., Eyler, C.E., Macswords, J., Wu, Q., Vasanji, A., McLendon, R.E., Hjelmeland, A.B., et al. (2010). Integrin alpha 6 regulates glioblastoma stem cells. Cell Stem Cell 6, 421-432.

Lathia, J.D., Mack, S.C., Mulkearns-Hubert, E.E., Valentim, C.L., and Rich, J.N. (2015). Cancer stem cells in glioblastoma. Genes Dev 29, 1203-1217.

Li, J., Haque, M., Shang, C., Hassan, B., Liu, D., Chen, W., and Lai, R. (2021). Identification and Characterization of Cancer Stem-Like Cells in ALK-Positive Anaplastic Large Cell Lymphoma Using the SORE6 Reporter. Curr Issues Mol Biol 43, 543-557.

Li, Y., Han, J., Zhang, Y., Cao, F., Liu, Z., Li, S., Wu, J., Hu, C., Wang, Y., Shuai, J., et al. (2016). Structural basis for activity regulation of MLL family methyltransferases. Nature 530, 447-452.

Liau, B.B., Sievers, C., Donohue, L.K., Gillespie, S.M., Flavahan, W.A., Miller, T.E., Venteicher, A.S., Hebert, C.H., Carey, C.D., Rodig, S.J., et al. (2017). Adaptive Chromatin Remodeling Drives Glioblastoma Stem Cell Plasticity and Drug Tolerance. Cell Stem Cell 20, 233-246 e237.

Lim, D.A., Huang, Y.C., Swigut, T., Mirick, A.L., Garcia-Verdugo, J.M., Wysocka, J., Ernst, P., and Alvarez-Buylla, A. (2009). Chromatin remodelling factor Mll1 is essential for neurogenesis from postnatal neural stem cells. Nature 458, 529-533.

Lu, K., Tao, H., Si, X., and Chen, Q. (2018). The Histone H3 Lysine 4 Presenter WDR5 as an Oncogenic Protein and Novel Epigenetic Target in Cancer. Front Oncol 8, 502.

Luo, B., Cheung, H.W., Subramanian, A., Sharifnia, T., Okamoto, M., Yang, X., Hinkle, G., Boehm, J.S., Beroukhim, R., Weir, B.A., et al. (2008). Highly parallel identification of essential genes in cancer cells. Proc Natl Acad Sci U S A 105, 20380-20385.

Mack, S.C., Singh, I., Wang, X., Hirsch, R., Wu, Q., Villagomez, R., Bernatchez, J.A., Zhu, Z., Gimple, R.C., Kim, L.J.Y., et al. (2019). Chromatin landscapes reveal developmentally encoded transcriptional states that define human glioblastoma. J Exp Med 216, 1071-1090.

Mahar Doan, K.M., Humphreys, J.E., Webster, L.O., Wring, S.A., Shampine, L.J., Serabjit-Singh, C.J., Adkison, K.K., and Polli, J.W. (2002). Passive permeability and P-glycoprotein-mediated efflux differentiate central nervous system (CNS) and non-CNS marketed drugs. J Pharmacol Exp Ther 303, 1029-1037.

Mehta, S., Huillard, E., Kesari, S., Maire, C.L., Golebiowski, D., Harrington, E.P., Alberta, J.A., Kane, M.F., Theisen, M., Ligon, K.L., et al. (2011). The central nervous system-restricted transcription factor Olig2 opposes p53 responses to genotoxic damage in neural progenitors and malignant glioma. Cancer Cell 19, 359-371. 
Menendez, S.T., Rey, V., Martinez-Cruzado, L., Gonzalez, M.V., Morales-Molina, A., Santos, L., Blanco, V., Alvarez, C., Estupinan, O., Allonca, E., et al. (2020). SOX2 Expression and Transcriptional Activity Identifies a Subpopulation of Cancer Stem Cells in Sarcoma with Prognostic Implications. Cancers (Basel) 12.

Miller, T.E., Liau, B.B., Wallace, L.C., Morton, A.R., Xie, Q., Dixit, D., Factor, D.C., Kim, L.J.Y., Morrow, J.J., Wu, Q., et al. (2017). Transcription elongation factors represent in vivo cancer dependencies in glioblastoma. Nature 547, 355-359.

Mitchell, K., Troike, K., Silver, D.J., and Lathia, J.D. (2021). The evolution of the cancer stem cell state in glioblastoma: emerging insights into the next generation of functional interactions. Neuro Oncol 23, 199-213.

Oasa, S., Vukojevic, V., Rigler, R., Tsigelny, I.F., Changeux, J.P., and Terenius, L. (2020). A strategy for designing allosteric modulators of transcription factor dimerization. Proc Natl Acad Sci U S A 117, 2683-2686.

Padua, D., Barros, R., Amaral, A.L., Mesquita, P., Freire, A.F., Sousa, M., Maia, A.F., Caiado, I., Fernandes, H., Pombinho, A., et al. (2020). A SOX2 Reporter System Identifies Gastric Cancer Stem-Like Cells Sensitive to Monensin. Cancers (Basel) 12.

Patel, A., Vought, V.E., Dharmarajan, V., and Cosgrove, M.S. (2008). A conserved argininecontaining motif crucial for the assembly and enzymatic activity of the mixed lineage leukemia protein-1 core complex. J Biol Chem 283, 32162-32175.

Pudelko, L., Rouhi, P., Sanjiv, K., Gad, H., Kalderen, C., Hoglund, A., Squatrito, M., Schuhmacher, A.J., Edwards, S., Hagerstrand, D., et al. (2017). Glioblastoma and glioblastoma stem cells are dependent on functional MTH1. Oncotarget 8, 84671-84684.

Rheinbay, E., Suva, M.L., Gillespie, S.M., Wakimoto, H., Patel, A.P., Shahid, M., Oksuz, O., Rabkin, S.D., Martuza, R.L., Rivera, M.N., et al. (2013). An aberrant transcription factor network essential for Wnt signaling and stem cell maintenance in glioblastoma. Cell Rep 3, 1567-1579.

Ruthenburg, A.J., Wang, W., Graybosch, D.M., Li, H., Allis, C.D., Patel, D.J., and Verdine, G.L. (2006). Histone H3 recognition and presentation by the WDR5 module of the MLL1 complex. Nat Struct Mol Biol 13, 704-712.

Shakya, S., Gromovsky, A.D., Hale, J.S., Knudsen, A.M., Prager, B., Wallace, L.C., Penalva, L.O.F., Brown, H.A., Kristensen, B.W., Rich, J.N., et al. (2021). Altered lipid metabolism marks glioblastoma stem and non-stem cells in separate tumor niches. Acta Neuropathol Commun 9, 101.

Shinsky, S.A., Monteith, K.E., Viggiano, S., and Cosgrove, M.S. (2015). Biochemical reconstitution and phylogenetic comparison of human SET1 family core complexes involved in histone methylation. J Biol Chem 290, 6361-6375.

Silver, D.J., Roversi, G.A., Bithi, N., Wang, S.Z., Troike, K.M., Neumann, C.K., Ahuja, G.K., Reizes, O., Brown, J.M., Hine, C., et al. (2021). Severe consequences of a high-lipid diet include hydrogen sulfide dysfunction and enhanced aggression in glioblastoma. J Clin Invest. 
Singh, D.K., Kollipara, R.K., Vemireddy, V., Yang, X.L., Sun, Y., Regmi, N., Klingler, S., Hatanpaa, K.J., Raisanen, J., Cho, S.K., et al. (2017). Oncogenes Activate an Autonomous Transcriptional Regulatory Circuit That Drives Glioblastoma. Cell Rep 18, 961-976.

Sun, Y., Bell, J.L., Carter, D., Gherardi, S., Poulos, R.C., Milazzo, G., Wong, J.W., Al-Awar, R., Tee, A.E., Liu, P.Y., et al. (2015). WDR5 Supports an N-Myc Transcriptional Complex That Drives a Protumorigenic Gene Expression Signature in Neuroblastoma. Cancer Res 75, 5143-5154.

Suva, M.L., Rheinbay, E., Gillespie, S.M., Patel, A.P., Wakimoto, H., Rabkin, S.D., Riggi, N., Chi, A.S., Cahill, D.P., Nahed, B.V., et al. (2014). Reconstructing and reprogramming the tumorpropagating potential of glioblastoma stem-like cells. Cell 157, 580-594.

Suva, M.L., Riggi, N., Janiszewska, M., Radovanovic, I., Provero, P., Stehle, J.C., Baumer, K., Le Bitoux, M.A., Marino, D., Cironi, L., et al. (2009). EZH2 is essential for glioblastoma cancer stem cell maintenance. Cancer Res 69, 9211-9218.

Tang, B., Raviv, A., Esposito, D., Flanders, K.C., Daniel, C., Nghiem, B.T., Garfield, S., Lim, L., Mannan, P., Robles, A.I., et al. (2015). A flexible reporter system for direct observation and isolation of cancer stem cells. Stem Cell Reports 4, 155-169.

Thon, N., Kreth, S., and Kreth, F.W. (2013). Personalized treatment strategies in glioblastoma: MGMT promoter methylation status. Onco Targets Ther 6, 1363-1372.

Tian, J., Teuscher, K.B., Aho, E.R., Alvarado, J.R., Mills, J.J., Meyers, K.M., Gogliotti, R.D., Han, C., Macdonald, J.D., Sai, J., et al. (2020). Discovery and Structure-Based Optimization of Potent and Selective WD Repeat Domain 5 (WDR5) Inhibitors Containing a Dihydroisoquinolinone Bicyclic Core. J Med Chem 63, 656-675.

Vaddi, P.K., Stamnes, M.A., Cao, H., and Chen, S. (2019). Elimination of SOX2/OCT4-Associated Prostate Cancer Stem Cells Blocks Tumor Development and Enhances Therapeutic Response. Cancers (Basel) 11.

Valor, L.M., and Hervas-Corpion, I. (2020). The Epigenetics of Glioma Stem Cells: A Brief Overview. Front Oncol 10, 602378.

Venkatesh, H.S., Johung, T.B., Caretti, V., Noll, A., Tang, Y., Nagaraja, S., Gibson, E.M., Mount, C.W., Polepalli, J., Mitra, S.S., et al. (2015). Neuronal Activity Promotes Glioma Growth through Neuroligin-3 Secretion. Cell 161, 803-816.

Wang, F., Zhang, J., Ke, X., Peng, W., Zhao, G., Peng, S., Xu, J., Xu, B., and Cui, H. (2020). WDR5-Myc axis promotes the progression of glioblastoma and neuroblastoma by transcriptional activating CARM1. Biochem Biophys Res Commun 523, 699-706.

Wysocka, J., Swigut, T., Milne, T.A., Dou, Y., Zhang, X., Burlingame, A.L., Roeder, R.G., Brivanlou, A.H., and Allis, C.D. (2005). WDR5 associates with histone H3 methylated at K4 and is essential for H3 K4 methylation and vertebrate development. Cell 121, 859-872.

Xue, H., Yao, T., Cao, M., Zhu, G., Li, Y., Yuan, G., Chen, Y., Lei, M., and Huang, J. (2019). Structural basis of nucleosome recognition and modification by MLL methyltransferases. Nature $573,445-449$. 
Yoo, S., and Bieda, M.C. (2014). Differences among brain tumor stem cell types and fetal neural stem cells in focal regions of histone modifications and DNA methylation, broad regions of modifications, and bivalent promoters. BMC Genomics 15, 724.

Zhang, W., Couldwell, W.T., Simard, M.F., Song, H., Lin, J.H., and Nedergaard, M. (1999). Direct gap junction communication between malignant glioma cells and astrocytes. Cancer Res 59, 1994-2003.

Zhang, X., Zheng, X., Yang, H., Yan, J., Fu, X., Wei, R., Xu, X., Zhang, Z., Yu, A., Zhou, K., et al. (2018). Piribedil disrupts the MLL1-WDR5 interaction and sensitizes MLL-rearranged acute myeloid leukemia (AML) to doxorubicin-induced apoptosis. Cancer Lett 431, 150-160.

Zhao, F.Y., Zhang, Q., Wang, J.M., Jiang, J.Y., Huyan, L.Y., Liu, B.Q., Yan, J., Li, C., and Wang, H.Q. (2021). BAG3 epigenetically regulates GALNT10 expression via WDR5 and facilitates the stem cell-like properties of platin-resistant ovarian cancer cells. Biochim Biophys Acta Mol Cell Res 1868, 119077. 
Fiqure bjoRxiv preprint doi: https://doi.org/10.1101/2021.09.20.461125; this version posted September 23, 2021. The copyright holder for this preprint

Figure (which was not certified by peer review) is the author/funder, who has granted bioRxiv a license to display the preprint in perpetuity. It is made
available under aCC-BY-NC-ND 4.0 International license.

A

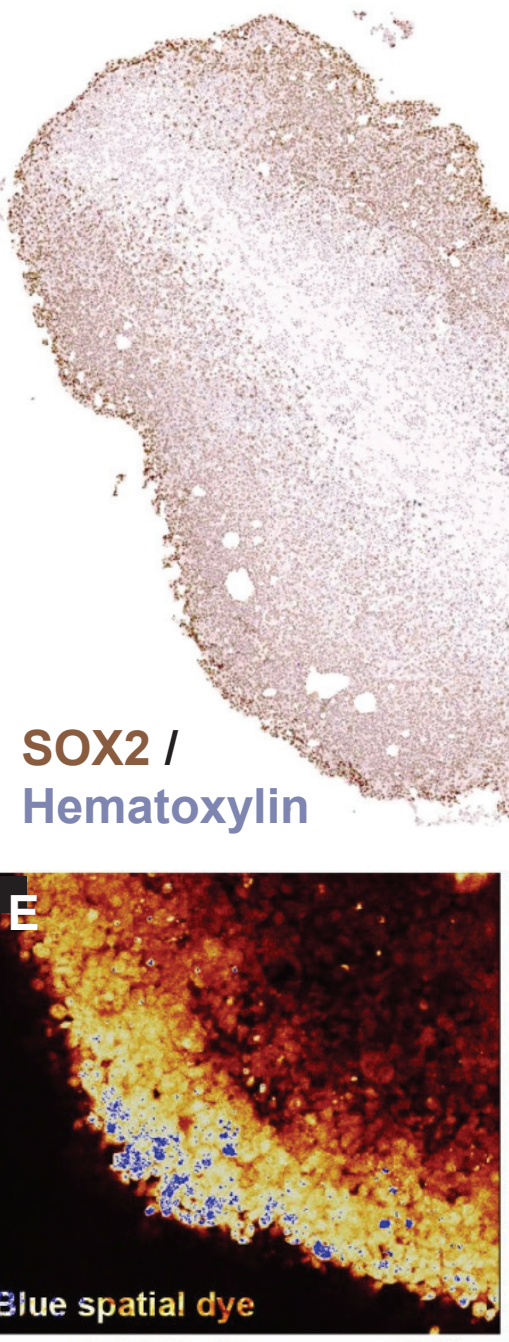

GBM Organoid Wide Field

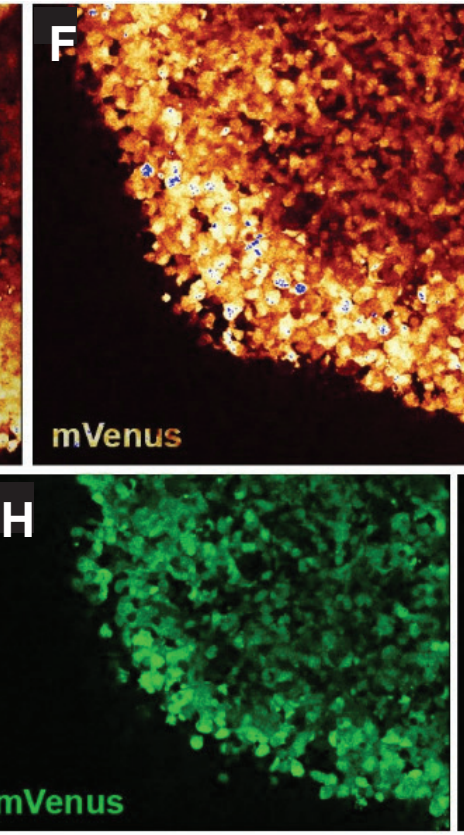

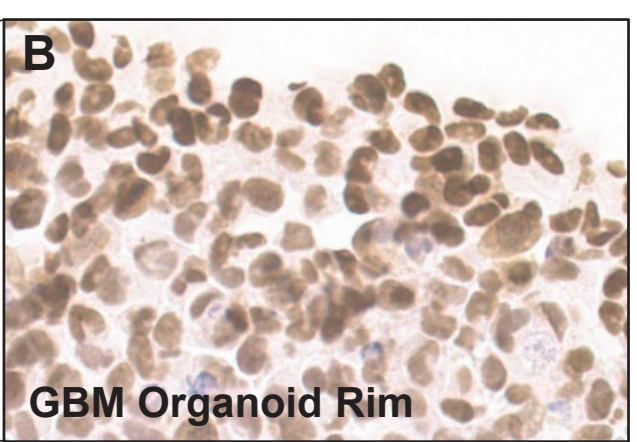

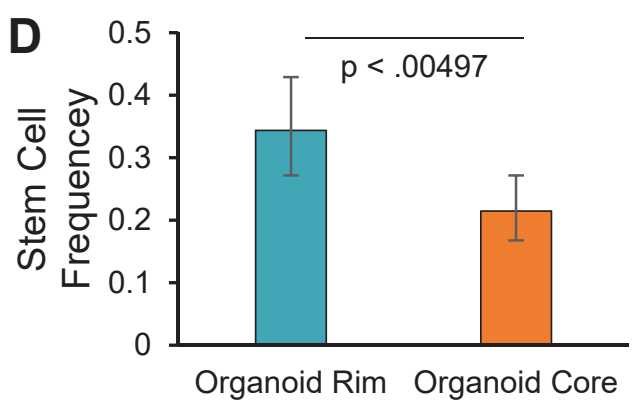

FACS

Separation

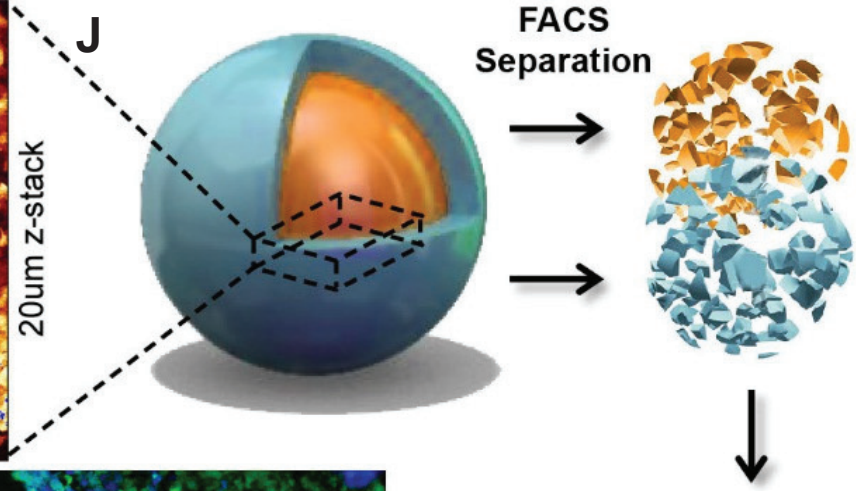

Barcode Sequencing

\& Statistical Analysis

K
Gene Rank vs. -Log10(p-value)

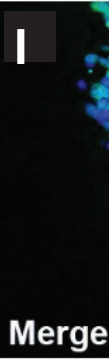

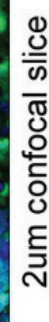

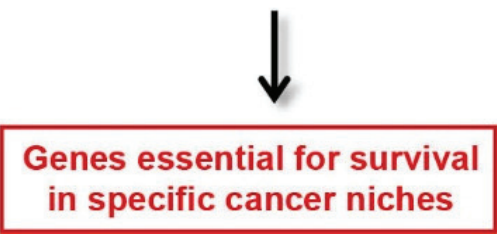

Genes essential for survival in specific cancer niches

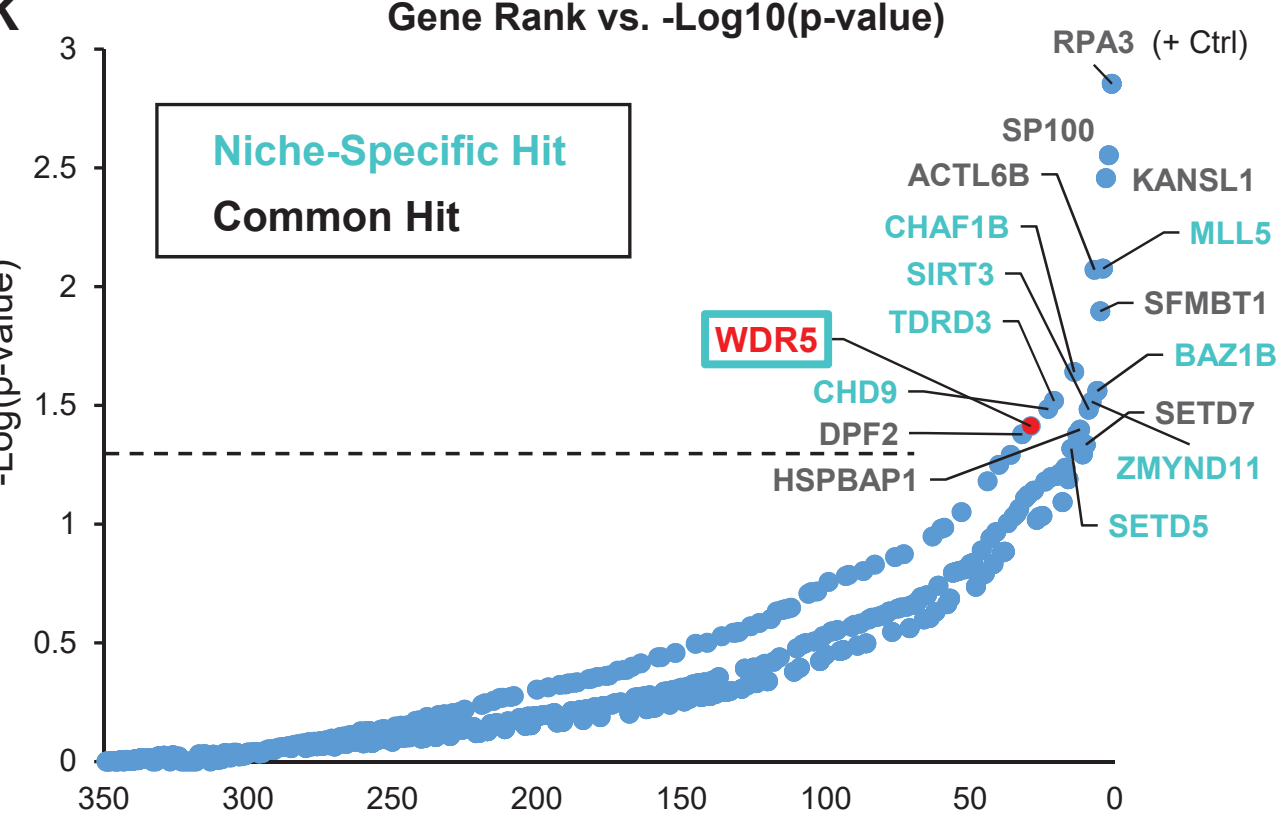

$\mathbf{L}$

Distribution of essential gene hits

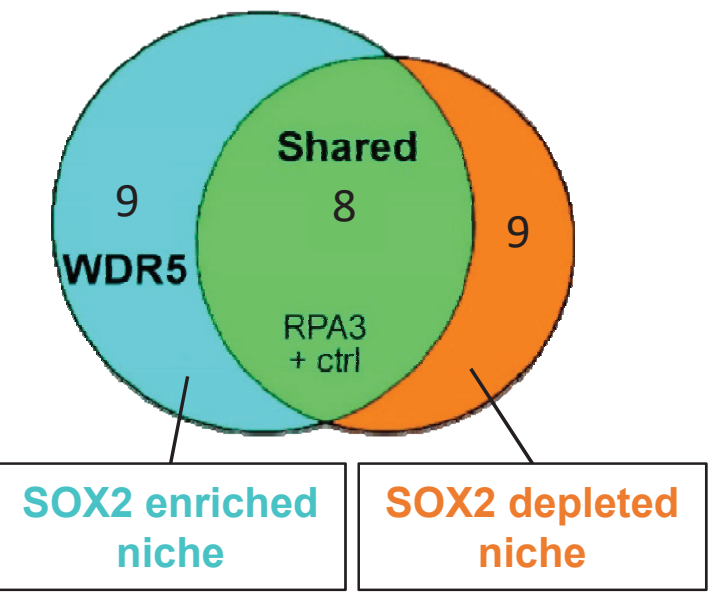


bioRxiv preprint doi: https://doi.org/10.1101/2021.09.20.461125; this version posted September 23, 2021. The copyright holder for this preprint - (which was not certified by peer review) is the author/funder, who has granted bioRxiv a license to display the preprint in perpetuity. It is made

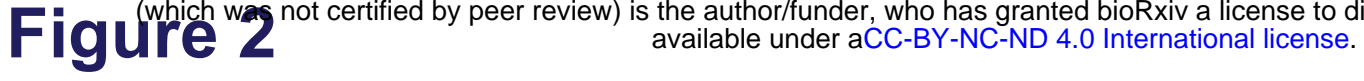

A

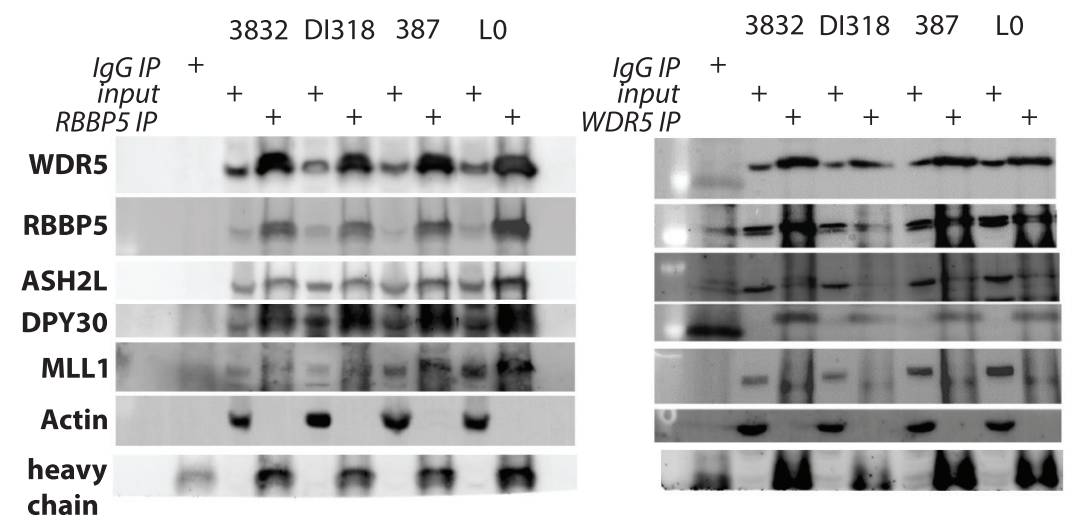

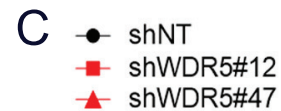

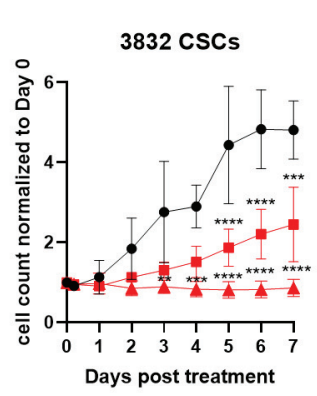

E

3832 CSCs

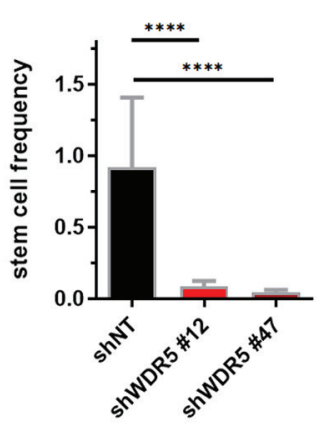

DI318 CsCs

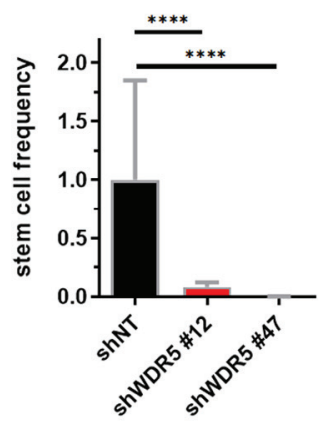

Lo cscs
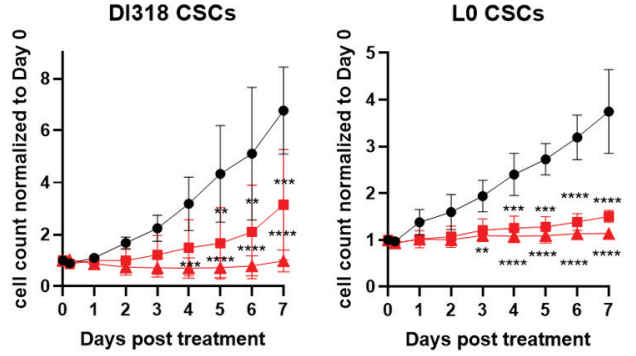

3832 csCs

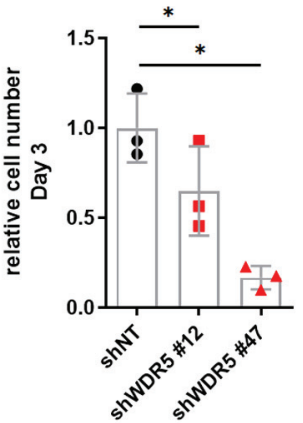

B

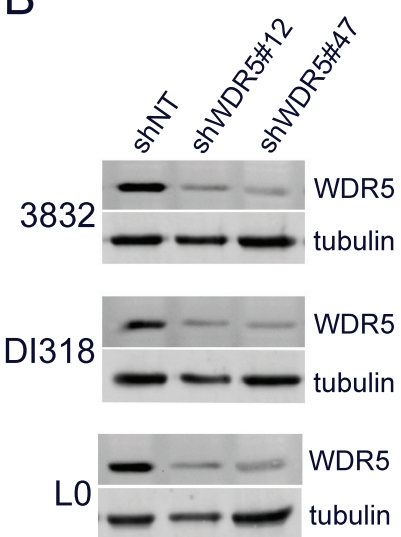

F

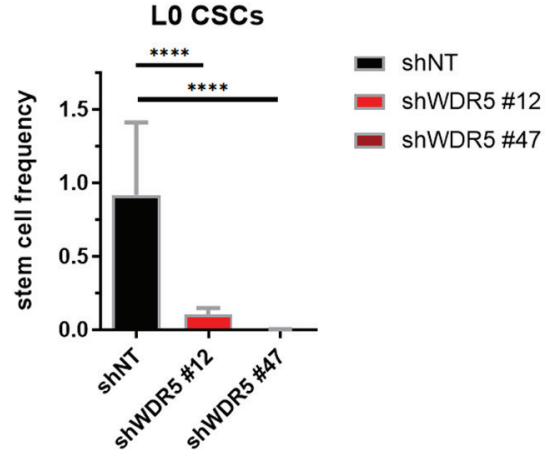

\begin{tabular}{|c|c|c|c|}
\hline $\begin{array}{c}\text { Cell } \\
\text { model }\end{array}$ & \multicolumn{3}{|c|}{$\begin{array}{c}\text { Average sphere forming } \\
\text { frequency }\end{array}$} \\
\hline & shNT & $\begin{array}{c}\text { shWDR5 } \\
\# 12\end{array}$ & $\begin{array}{c}\text { shWDR5 } \\
\# 47\end{array}$ \\
\hline $\begin{array}{c}\mathbf{3 8 3 2} \\
(\mathrm{n}=4)\end{array}$ & 1 in 1.1 & 1 in 6.2 & 1 in 25.0 \\
\hline $\begin{array}{c}\text { DI318 } \\
(\mathrm{n}=5)\end{array}$ & 1 in 1.4 & 1 in 4.3 & 1 in 27.7 \\
\hline $\begin{array}{c}\text { L0 } \\
(\mathrm{n}=4)\end{array}$ & 1 in 1.8 & 1 in 13.9 & 1 in 62.5 \\
\hline
\end{tabular}
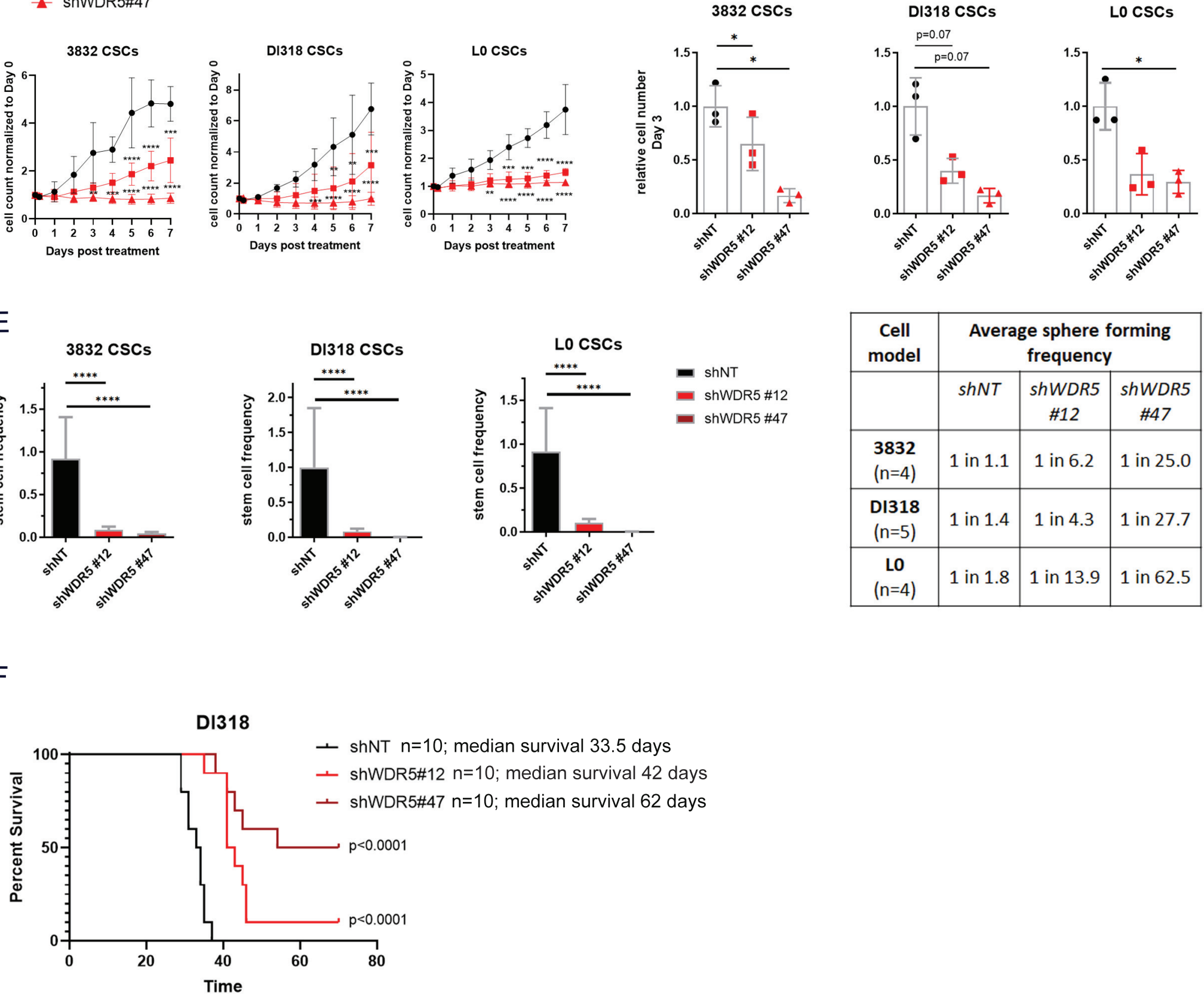
bioRxiv preprint doi: https://doi.org/10.1101/2021.09.20.461125; this version posted September 23, 2021. The copyright holder for this preprint Figure (which was not certified by peer review) is the author/funder, who has granted bioRxiv a license to display the preprint in perpetuity. It is made Figure 3 available under aCC-BY-NC-ND 4.0 International license.

A

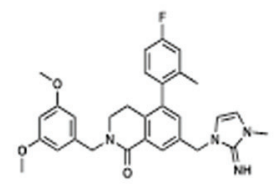

C16

B

B GBM cscs
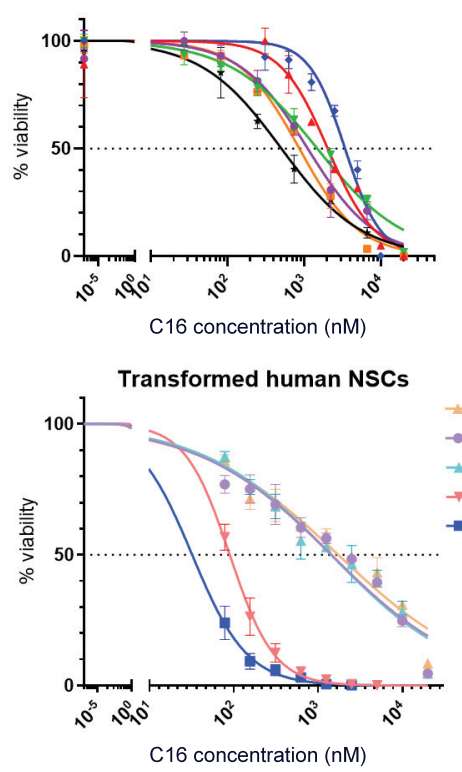

F

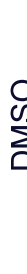

G

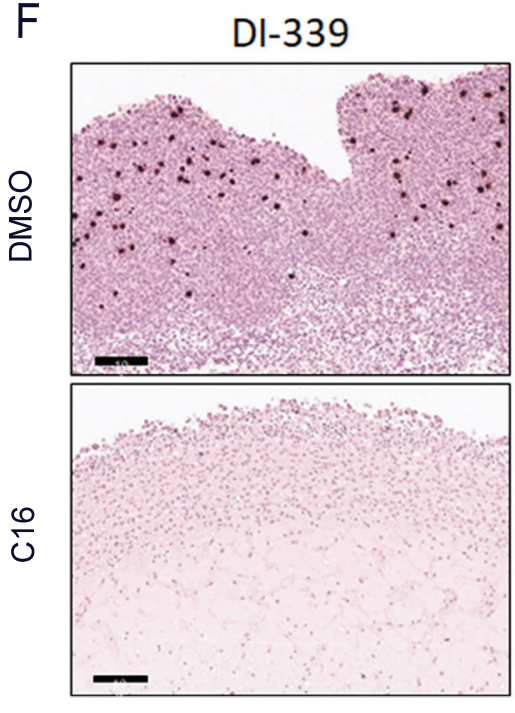

$\rightarrow \mathrm{D} 1318$

- 387

- 3832

$\rightarrow-12$

- GBM23

$\rightarrow$ LO

- $\mathrm{PhT}$

$\rightarrow$ PhTCC

- PhTCC+Ras

7 PhTCC+Myc

- PhTCC+Myc+Ras
C

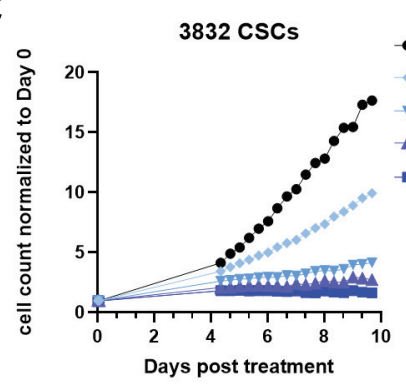

DI318 csCs

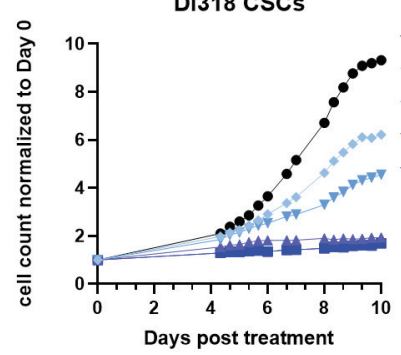

LO CSCs

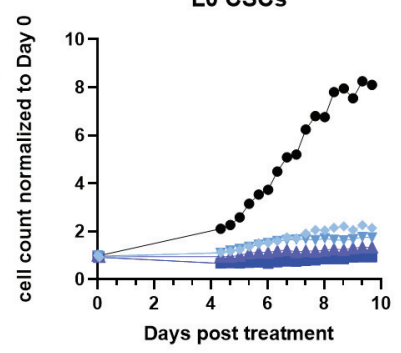

D

- DMSO

- $\mathrm{C} 160.625 \mu \mathrm{M}$

* $\mathrm{C} 161.25 \mu \mathrm{M}$

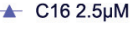

- $\mathrm{C} 165 \mathrm{MM}$

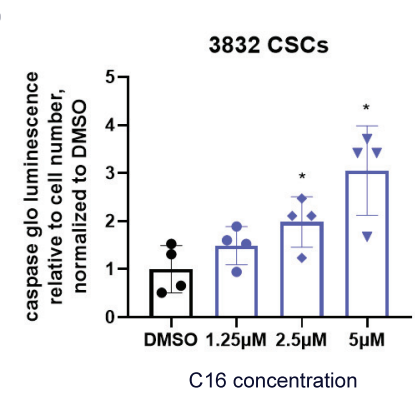

DI318 CSCs

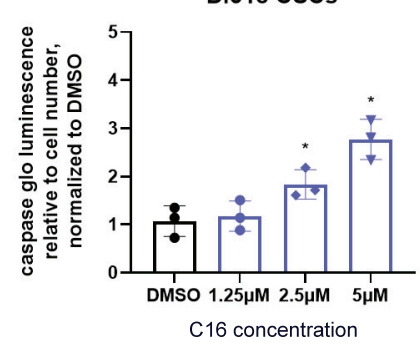

Lo csCs

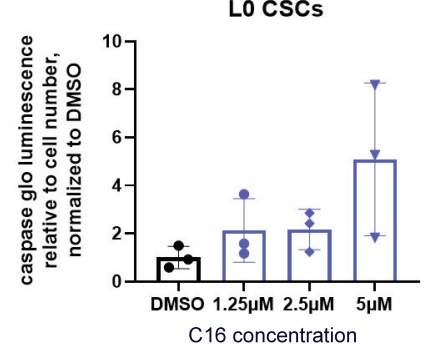

E

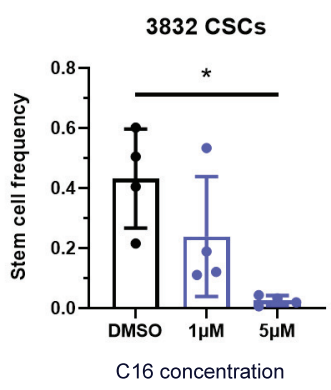

DI318 CsCs

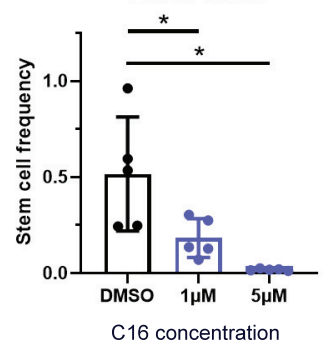

LO CSCs

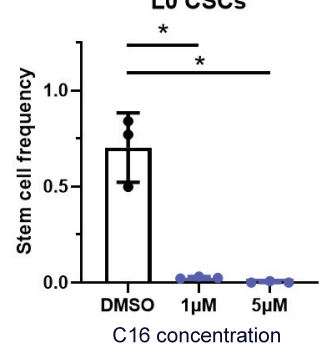

CCF4674

DI318
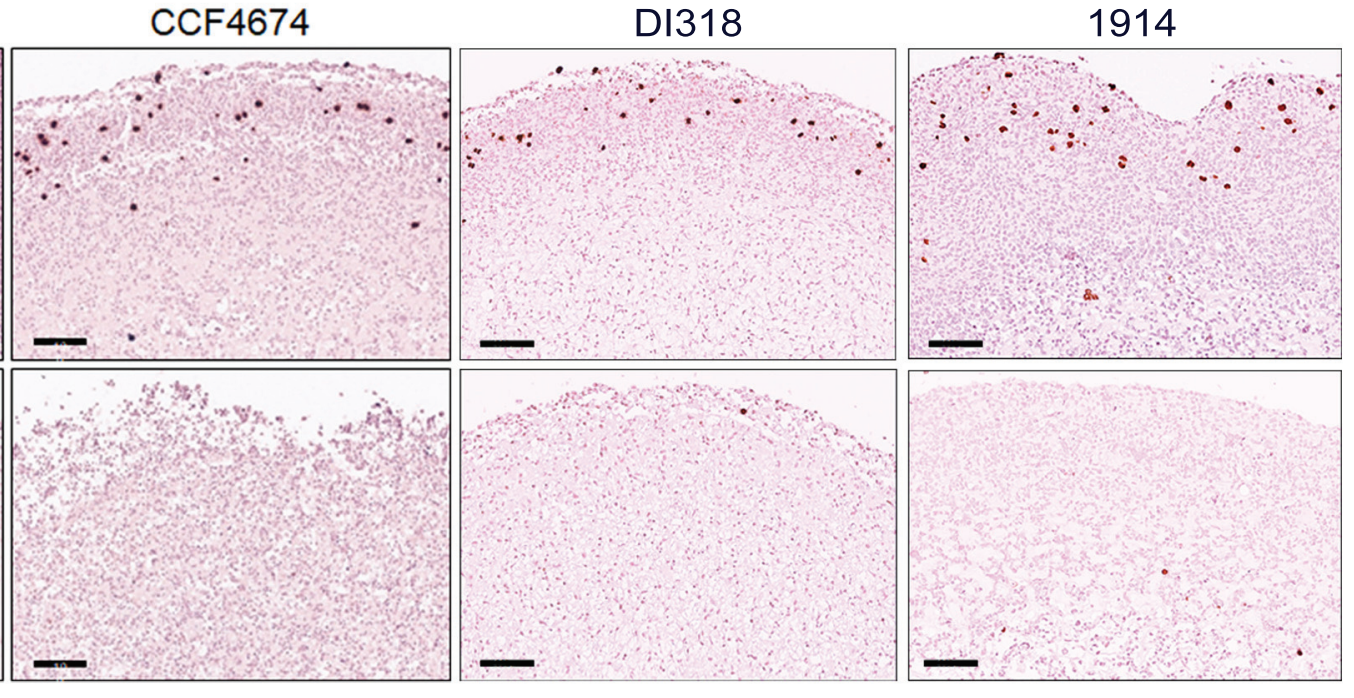

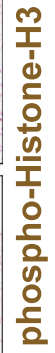

$\mathrm{H}$
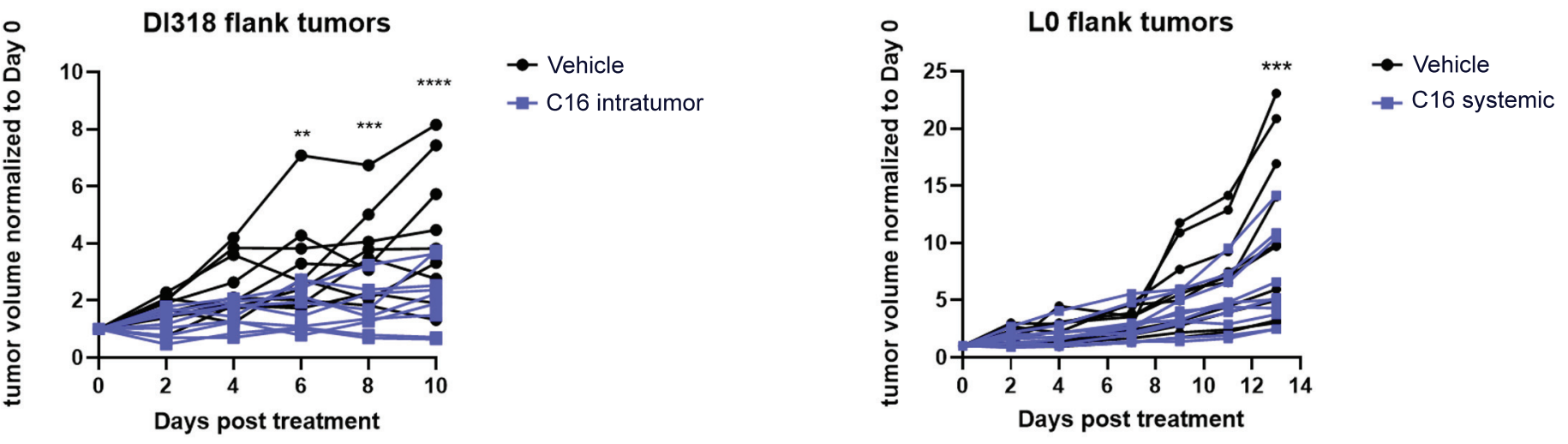
B
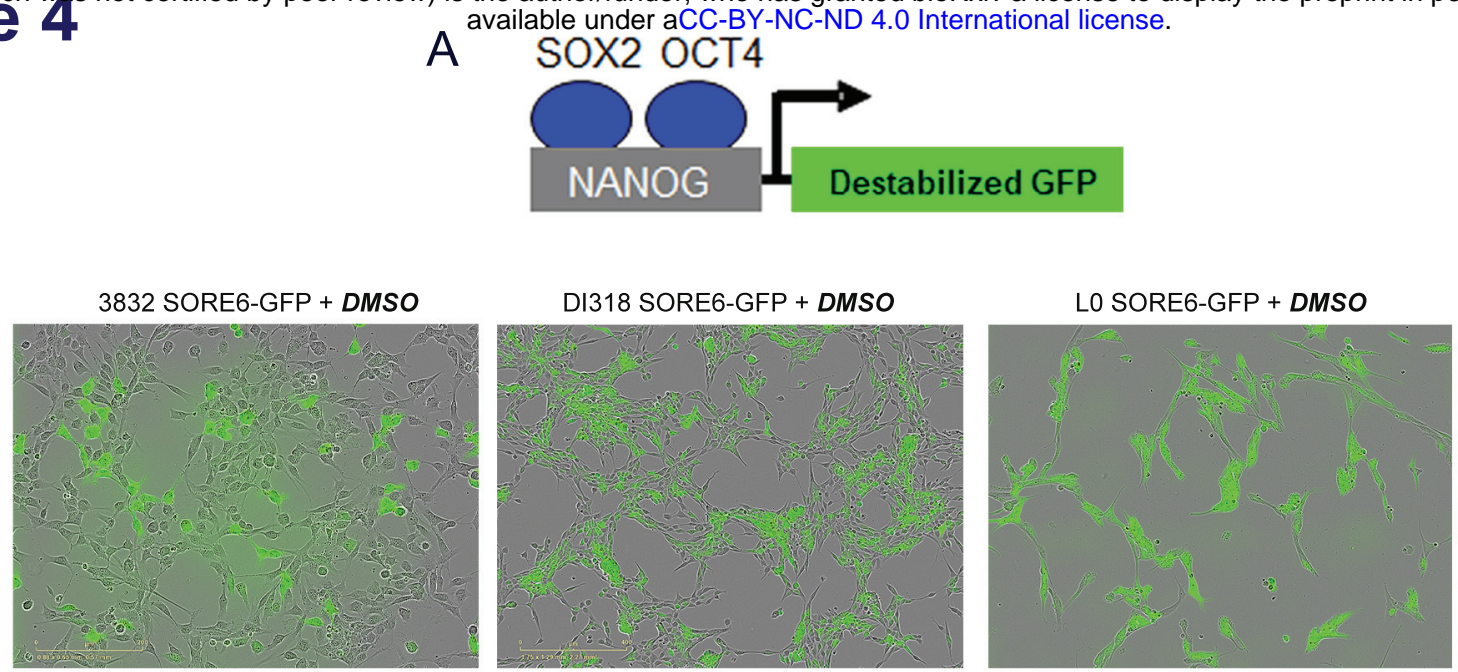

3832 SORE6-GFP + 2.5uM C16

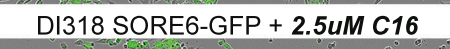

LO SORE6-GFP + 2.5uM C16
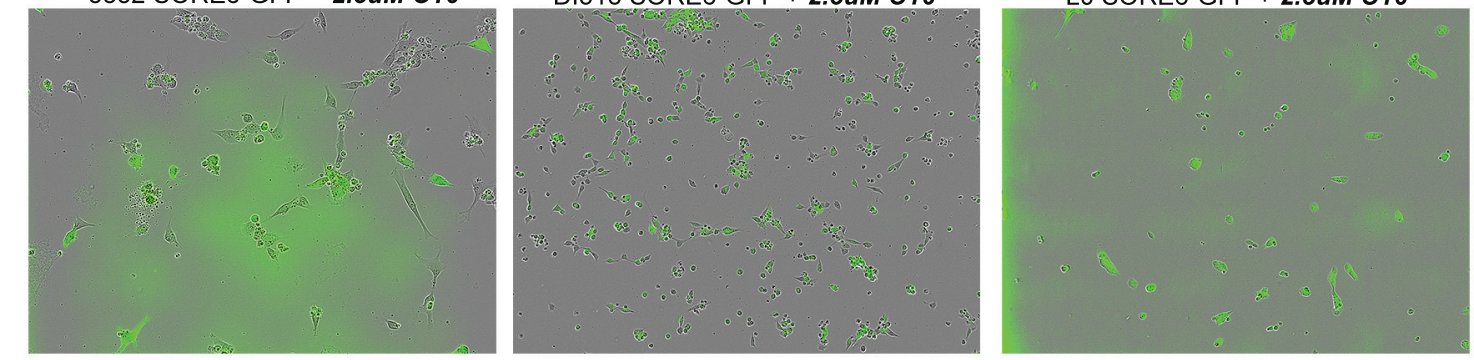

3832 SORE6-GFP + 5uM C16

DI318 SORE6-GFP + 5uM C16

L0 SORE6-GFP + 5uM C16
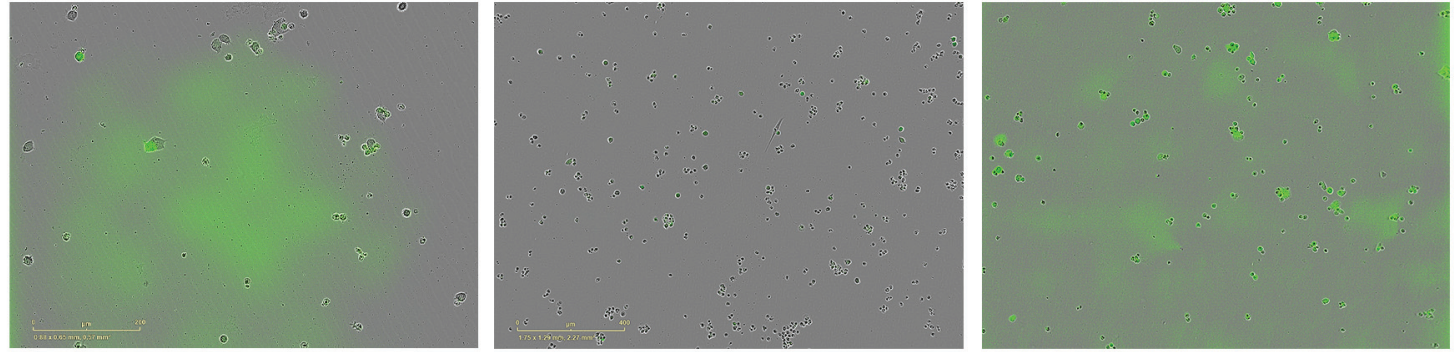

C

\section{DI318}

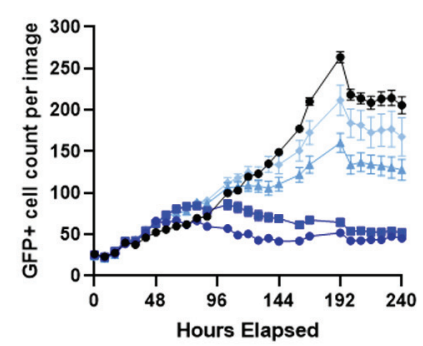

3832
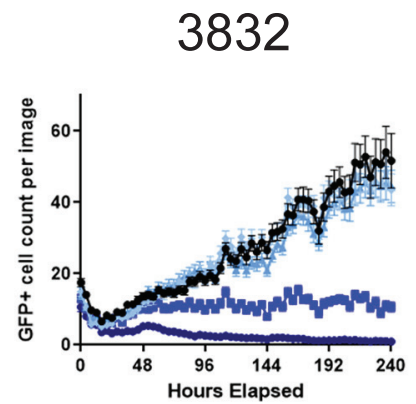

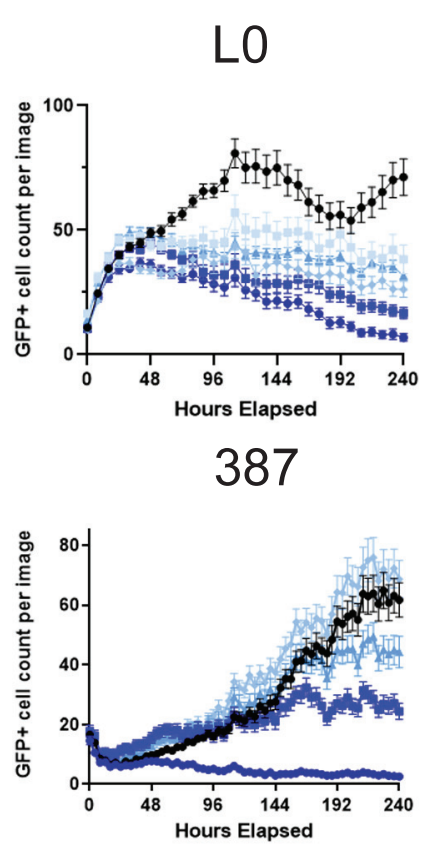

- DMSO

C16 $0.31 \mu \mathrm{M}$

- C16 $0.63 \mu \mathrm{M}$

4 C16 $1.25 \mu \mathrm{M}$

$-\mathrm{C} 162.5 \mu \mathrm{M}$

- $\mathrm{C} 165 \mu \mathrm{M}$

D

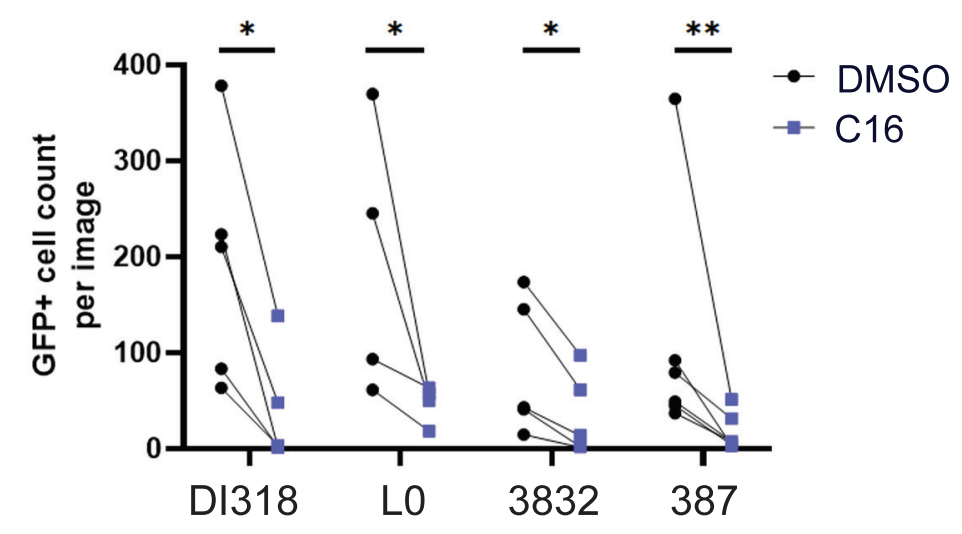

$\underset{\mathrm{C} 16}{\mathrm{DMSO}}+{ }_{+}^{+}+{ }_{+}^{+}$ 
A

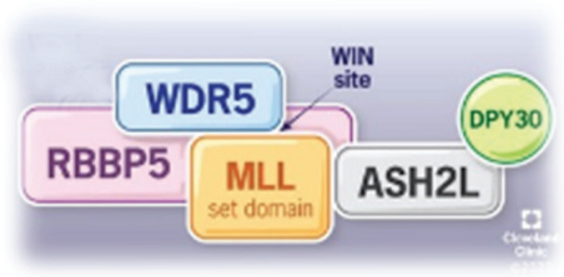

C

RBBP5 pulldown
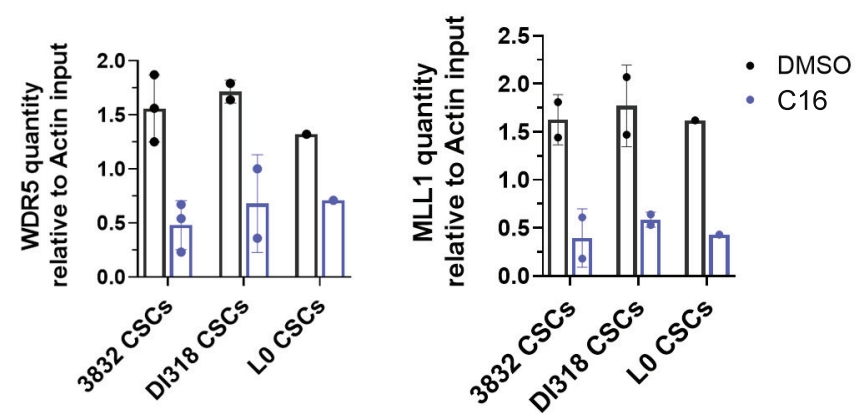

B

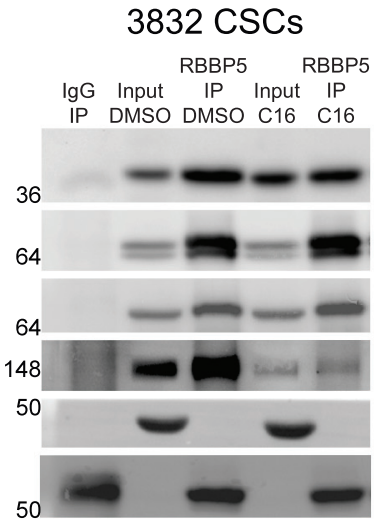

DI318 CSCs

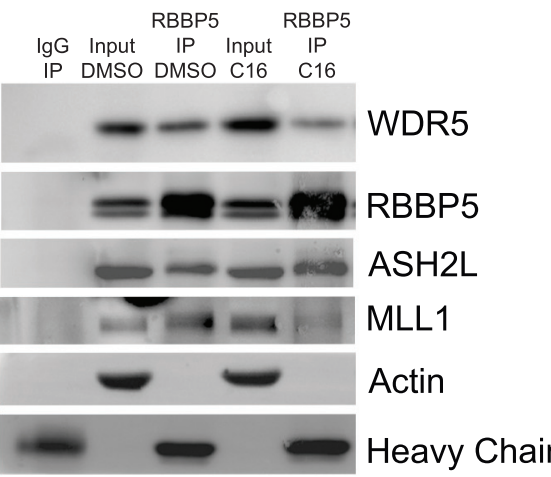

D
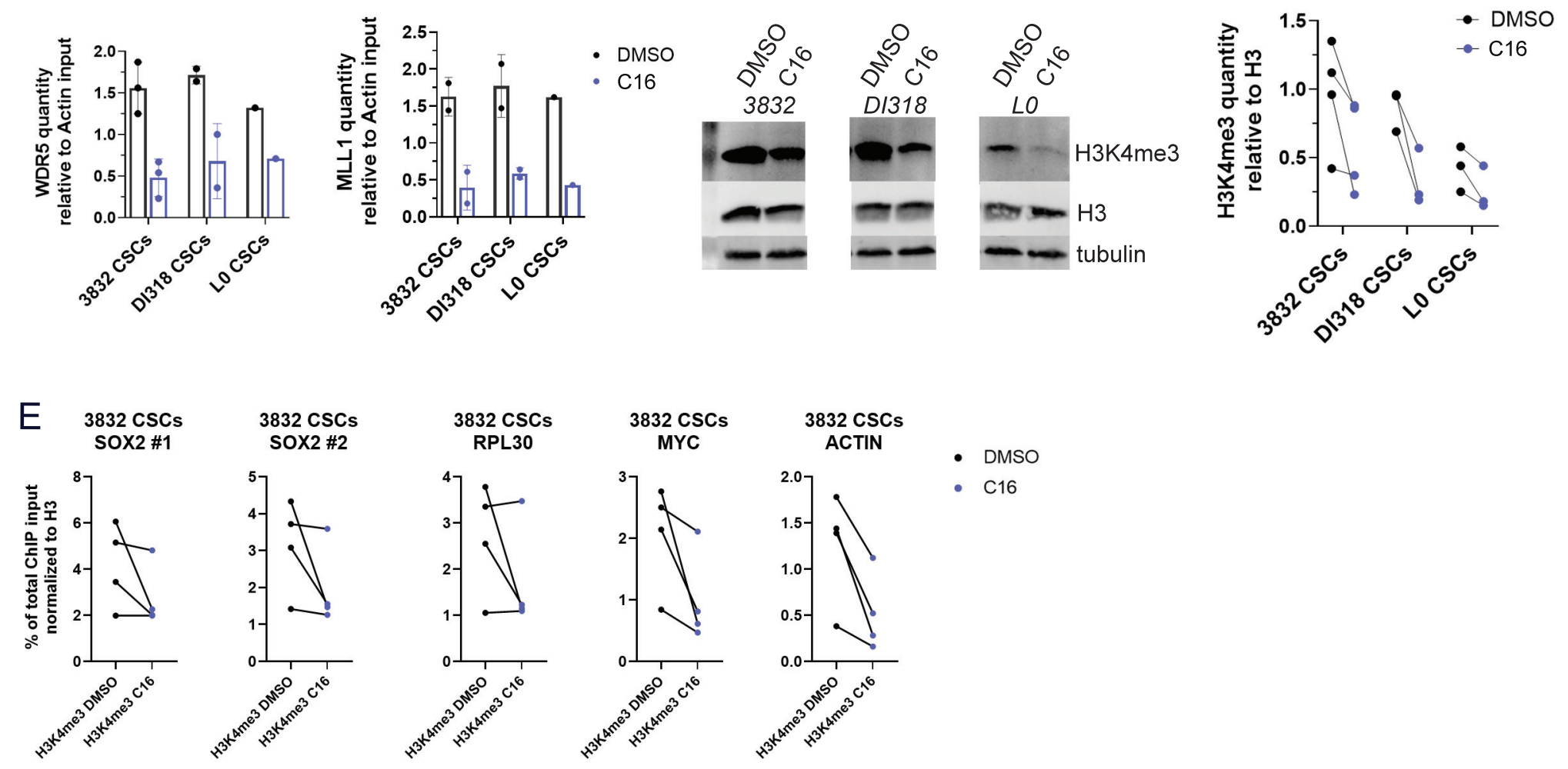